\title{
Comparison of Raindrop Size Distribution Measurements by Collocated Disdrometers
}

\author{
ALI TOKAY \\ Joint Center for Earth Systems Technology, University of Maryland, Baltimore County, Baltimore, and NASA Goddard \\ Space Flight Center, Greenbelt, Maryland \\ WALTER A. PETERSEN \\ NASA Goddard Space Flight Center, Wallops Flight Facility, Wallops Island, Virginia \\ PATRICK GATLIN \\ NASA Marshall Space Flight Center, Huntsville, Alabama \\ MATTHEW Wingo \\ National Space Science and Technology Center, Earth System Science Center, The University of Alabama \\ in Huntsville, Huntsville, Alabama
}

(Manuscript received 13 August 2012, in final form 26 February 2013)

\begin{abstract}
An impact-type Joss-Waldvogel disdrometer (JWD), a two-dimensional video disdrometer (2DVD), and a laser optical OTT Particle Size and Velocity (PARSIVEL) disdrometer (PD) were used to measure the raindrop size distribution (DSD) over a 6-month period in Huntsville, Alabama. Comparisons indicate event rain totals for all three disdrometers that were in reasonable agreement with a reference rain gauge. In a relative sense, hourly composite DSDs revealed that the JWD was more sensitive to small drops $(<1 \mathrm{~mm})$, while the PD appeared to severely underestimate small drops less than $0.76 \mathrm{~mm}$ in diameter. The JWD and 2DVD measured comparable number concentrations of midsize drops (1-3 mm) and large drops (3-5 mm), while the PD tended to measure relatively higher drop concentrations at sizes larger than $2.44 \mathrm{~mm}$ in diameter. This concentration disparity tended to occur when hourly rain rates and drop counts exceeded $2.5 \mathrm{~mm} \mathrm{~h}^{-1}$ and $400 \mathrm{~min}^{-1}$, respectively. Based on interactions with the PD manufacturer, the partially inhomogeneous laser beam is considered the cause of the PD drop count overestimation. PD drop fall speeds followed the expected terminal fall speed relationship quite well, while the 2DVD occasionally measured slower drops for diameters larger than $2.4 \mathrm{~mm}$, coinciding with events where wind speeds were greater than $4 \mathrm{~m} \mathrm{~s}^{-1}$. The underestimation of small drops by the PD had a pronounced effect on the intercept and shape of parameters of gamma-fitted DSDs, while the overestimation of midsize and larger drops resulted in higher mean values for PD integral rain parameters.
\end{abstract}

\section{Introduction}

Knowledge of the raindrop size distribution (DSD) is essential for many applications in various disciplines of Earth sciences. For example, rainfall is a key component of Earth's water and energy cycles and its intensity and duration are of interest to a wide variety of Earth science and engineering disciplines. While rain gauges

Corresponding author address: Ali Tokay, NASA Goddard Space Flight Center, Code 612.0, Greenbelt, MD 20771.

E-mail: ali.tokay-1@nasa.gov can directly measure rain intensity and accumulation at a point, regional to global mapping of rainfall relies heavily on measurements that include ground-based radar and satellite remote sensing. These remote sensing measurements necessarily employ empirical relations and underlying assumptions that are directly related to and affected by characteristics of the DSD.

The accuracy of the rainfall estimates using singlepolarization radar measurements traditionally relies on the appropriateness of derived radar rainfall relations including radar reflectivity-rain-rate relationships (i.e., the $Z-R$ relation). Both radar measurements and 
rainfall are integral products of the DSD and a surfacebased disdrometer is often employed to derive $Z-R$ relations for a climate region, a particular weather system (e.g., frontal and tropical), or even a segment of a storm (Atlas et al. 1999; Radhakrishna and Narayana Rao 2010). The highly variable nature of the DSD, for example from one weather system to another or between convective and stratiform segments of the same storm, results in substantial differences in derived $Z-R$ relations. Considering the disdrometer-based $Z-R$ relations, the variability in the $Z-R$ also depends on the choice of disdrometers (e.g., impact type and optical), method of derivation (e.g., linear versus nonlinear least squares fit), and the data processing techniques (e.g., time versus rain rate-based averaging DSD observations) (Campos and Zawadzki 2000; Tokay et al. 2001; Lee and Zawadzki 2005a,b).

For the dual-polarization radars, disdrometer observations are often employed in deriving relationships between polarimetric radar observables such as reflectivity at horizontal polarization ( $\mathrm{Zh})$, differential reflectivity (Zdr), and specific differential phase (Kdp) and rain rate (e.g., Bringi and Chandrasekar 2001; Tokay et al. 2002; Brandes et al. 2002; Bringi et al. 2003; and many others). Based on combinations of the polarimetric variables, a hybrid algorithm can then be developed for estimating rainfall (Cifelli et al. 2002; Bringi et al. 2002). The quality of polarimetric radar observables is critical for the accuracy of rainfall estimation. One of the numerous methods to quality control radar measurements uses a disdrometer-derived consistency equation among the three variables (Scarchilli et al. 1996; Ryzhkov et al. 2005).

Disdrometer observations are often employed to derive the parameters of model DSDs. The parametric form of the DSD (e.g., gamma, exponential, or lognormal distribution models) plays an important role in both active and passive satellite-based microwave sensor rainfall estimation. For example, the National Aeronautics and Space Administration (NASA)'s Global Precipitation Measurement (GPM) mission will launch its core satellite in 2014, carrying a dual-frequency precipitation radar (DPR) (Hou et al. 2008). In fact, efforts are already underway to demonstrate the DPR algorithm for the dual-frequency retrievals of the DSD (Mardiana et al. 2004; Meneghini and Liao 2007). In a related fashion, there have been multiparameter radar-based efforts to determine DSD variables from dual-polarization radar (Bringi et al. 2003, 2002; Zhang et al. 2001; Thurai et al. 2012) and from vertically pointing radars (Williams et al. 2000; Cifelli et al. 2002). The main motivation in these studies is to better estimate the surface rainfall using a parametric form of the DSD and more accurate estimation of the parameters associated with the particular DSD model used.

Disdrometer measurements are often used to determine the accuracy of the DSD retrieval from spaceborne radar measurements. Munchak and Tokay (2008), for instance, employed the impact-type Joss-Waldvogel disdrometer (JWD) observations to simulate the retrieval of parameters of the DSD from DPR. They used a three-parameter gamma distribution to represent the DSD in mathematical form. The gamma distribution has also been employed by the NASA's Tropical Rainfall Measuring Mission (TRMM) precipitation radar (PR; Iguchi et al. 2000; Kozu et al. 2009a,b) and the GPM DPR (Nakamura and Iguchi 2007) algorithm teams. The gamma-model DSD is expressed as

$$
N(D)=N_{0} D^{m} \exp (-\Lambda D),
$$

where $N_{0}, m$, and $\Lambda$ are intercept, shape, and slope parameters, respectively and $D$ is the drop diameter. Kozu et al. (2009a) employed $Z=A R^{b}$ relations, where $A$ is the coefficient and $b$ is the exponent, which were originally derived mostly from disdrometer observations in the tropics and produced a global average $Z-R$ for convective and stratiform rain. They then derived the power-law relation between slope and intercept parameters for convective and stratiform rain by fixing $m=3$. There is considerable interest in eliminating assumptions of a constant shape parameter in groundbased radar and GPM DPR algorithms alike. In this regard, considerable effort has been made in the past and present to find robust relationships between the three parameters of the gamma distribution (Zhang et al. 2001; Brandes et al. 2002; Vivekanandan et al. 2004). To this end, long-term observations of the disdrometer observations in various climate regimes are useful to test the robustness of the relations between the DSD parameters.

Disdrometer observations are useful for studying the highly variable nature of the DSD, at least at the point of measurement. Disdrometers can provide a temporally continuous record of the DSD and can address temporal variability of rainfall between consequent radar scans and satellite overpasses. The satellite- and radar-based DSD retrievals implicitly assume the homogeneity within the footprint and pixel space, respectively. Tokay and Bashor (2010) employed three JWD observations to study the variability of DSD and integral rain parameters within the radar pixel. The efforts are currently underway to study the DSD variability within TRMM PR footprint using JWD and laser optical Particle Size and Velocity (PARSIVEL) disdrometer (PD).

Disdrometer observations have a wide range of applications and hence users from various disciplines have 
a vested interest in understanding measurement accuracy and instruments' shortcomings. While accurate measurements of raindrop size and number characteristics across the full range of drop sizes are ideal, a particular drop size range may have higher importance for a specific application. In fact, the design and development of a disdrometer is sometimes driven by a particular measurement need. The JWD, for instance, was developed to measure radar reflectivity and therefore the measurement accuracy of midsize $(1-3 \mathrm{~mm}$ in diameter) and large (larger than $3 \mathrm{~mm}$ in diameter) drops was relatively more important than measuring small drops (less than $1 \mathrm{~mm}$ in diameter; Joss and Waldvogel 1967). As another example, the ability to image individual hydrometeors shape and fall velocity were a primary motivation for the development of the twodimensional video disdrometer (2DVD; Schönhuber et al. 2007). The identification of the precipitation type, measurement of size, and fall velocity of the hydrometeors, while keeping the costs low, were the main themes behind the development of the PD (Löffler-Mang and Joss 2000).

The three disdrometers (JWD, 2DVD, and PD) used for the present study are commercially available and have been used extensively in the literature. Nevertheless, there are other types of optical disdrometers that are either commercially available or are just developed for scientific use. Low-power radars can also be used as radar disdrometers even though they do not directly measure the individual hydrometeors. One example, the Precipitation Occurrence Sensor System (POSS), is a bistatic continuous wave X-band radar that was originally developed as an automated present weather sensor (Sheppard 1990). However, it has been widely used to measure the DSD (e.g., Lee and Zawadzki 2005a,b) and its small-scale spatial variability (Lee et al. 2009). Miriovsky et al. (2004) intended to quantify the spatial variability of radar reflectivity within the approximate spatial scale of a radar beam $\left(\sim 1 \mathrm{~km}^{2}\right)$ employing POSS, 2DVD, JWD, and two optical spectropluviometers (Hauser et al. 1984). They concluded that the interinstrument differences/errors in measuring the capability of the DSD did not allow determination of small-scale variability of radar reflectivity.

There have been a number of field studies designed to evaluate the performance of a disdrometer. Since each disdrometer has its own shortcomings, collocated reference rain gauges are often collocated with the disdrometers. Outside of the systematic errors mainly because of the wind, collocated gauges provide reliable rain totals (Tokay et al. 2010). However, good agreement between gauge and disdrometer rain totals does not guarantee good performance of the disdrometer.
For example, small drops often do not substantially contribute to the rainfall and therefore the instrument errors in these size ranges are masked in comparisons.

During TRMM field campaigns in east-central Florida and the Amazon basin of Brazil, the JWD and 2DVD were collocated to obtain higher accuracy and to ascertain uncertainty in the DSD estimates for radar rainfall estimation. While the disdrometers exhibited reasonable agreement with collocated rain gauge totals, there were noticeable differences between the JWD and 2DVD in the small and large size ends of the drop size spectrum (Tokay et al. 2001, 2002). Krajewski et al. (2006) conducted a field campaign where 2DVD, PD, and a dual-beam spectropluviometer (DBS) were collocated. Similarly, the disagreement between the disdrometers was at both ends of the drop size spectrum. While the differences in small drops were attributed to the measurement errors, differences in large drop counts were attributed to sampling errors.

Optical disdrometers can also measure the fall velocity of raindrops. Krajewski et al. (2006) reported that the majority of the fall speed measurements followed Gunn and Kinzer (1949, GK hereafter) terminal fall speed in DBS, but drops larger than $2 \mathrm{~mm}$ in diameter deviated from GK terminal fall speed in 2DVD and PD measurements.

The highly variable nature of the DSD results in sampling errors in disdrometer measurements. Time averaging can reduce the sampling errors, but it may also mask the intrinsic physical variability of the DSD. Collocating several of the same type of disdrometers as in the TRMM field campaigns can help to determine the sampling error even though rain is not a homogeneous process and each instrument has its own calibration. As such, Tokay et al. (2005) showed noticeable differences in rainfall estimations, which were derived from six collocated JWD observation-based radar rainfall relations. Cao et al. (2008), on the other hand, employed two collocated 2DVD observations to refine the relation between the slope and shape parameters of the gamma distribution. Reducing the sampling errors, they obtained a good agreement between radar and disdrometer DSD and rain parameters. Thurai et al. (2011) examined several rain events where two 2DVDs and two PDs were collocated. While there was a good agreement in derived DSD and rain parameters between the same types of disdrometers, PD had significantly higher mean mass diameter and rain rate than 2DVD, particularly at rain rates above $30 \mathrm{~mm} \mathrm{~h}^{-1}$.

In the last decade, there have been numerous developments in commercially available disdrometers, ostensibly to improve the breadth of measurement accuracy. Accordingly, this study provides a new comparison 
of the disdrometers' performance. This type of comparison is important because a complete understanding of instrument measurement uncertainty provides a framework for assessing the uncertainty in any retrieval of DSD, against which the disdrometers information is compared. Specifically, 6 months of collocated observations from JWD, 2DVD, and PD were collected in Huntsville, Alabama, and have been employed to investigate and characterize disdrometer performances for DSD and selected rain parameters. This study provides a brief description of each disdrometer type in section 2. Sections 3 and 4 describe the rainfall statistics and the observation site and data, respectively. A comparison of event rain totals between the disdrometers and the collocated rain gauges is presented in section 5, while hourly DSD characteristics observed by the disdrometers are given in section 6 . Section 7 shows a comparison of fall velocity measurements from the $2 \mathrm{DVD}$ and PD. A comparison of the selected DSD and rain parameters is demonstrated in section 8 and conclusions are presented in the last section.

\section{Disdrometers}

\section{a. Joss-Waldvogel disdrometer}

The impact-type JWD consists of sensor head and signal processing electronics (Joss and Waldvogel 1967). The sensor head has a cone, which is a Styrofoam body covered with an aluminum foil on the hitting surface. The cone has been equipped with wires, which are put on the hitting surface to help water drops leaving the surface and thus avoiding the formation of puddles. The RD-80 is a signal processing box that integrates the analog signal processing circuits and analog-to-digital (AD) converter into one unit. Prior to 2000 , the processor box (RD-69) had an analog output, which was connected to the AD (M. Weibel, Distromet, Ltd., 2011, personal communication). To position the sensor away from taller structures, a 100-m detachable cable can now be used to connect the sensor with the indoor signal processing box.

JWD measures the raindrop size from 0.3 to $5.5 \mathrm{~mm}$ in diameter with an accuracy of $\pm 5 \%$ if the drops are evenly distributed over the sensitive surface. The standard output includes drop counts at 20 uneven channels where the channel width ranges from 0.1 to $0.5 \mathrm{~mm}$ at 1-min intervals. A more detailed output with 127 size channel drop counts at 10 -s intervals is also available. The manufacturer provides a calibration table where the accuracy of 127 size bins is presented. The Distromet, Ltd. company has been manufacturing the JWD since 1972 and, based on our knowledge, the JWD has been used more than any other disdrometer in the literature. Additional information about the JWD can be found at the company website (http://www.distromet.com).

\section{b. Two-dimensional video disdrometer}

The 2DVD consists of an outdoor sensor unit containing dual-optical line scan cameras and an indoor user terminal. The current third-generation 2DVD, which is also referred to as the compact version because of its smaller dimensions and fewer number of components than previous versions, was first delivered to the GPM ground validation group in 2009. We are one of the first to use data from this compact 2DVD in addition to a companion study reported in Thurai et al. (2011). Note that the compact 2DVD was designed as an improvement to the second-generation low-profile unit (single optical bench, more rugged instrument) and that both the compact and low-profile units were developed to improve on the original taller 2DVD (Kruger and Krajewski 2002). Here, the compact and low-profile designs were driven by the need to reduce wind-induced measurement errors in response to Nespor et al. (2000). Like JWD, the 2DVD requires shelter and power.

The 2DVD measures the hydrometeor size, fall velocity, and shape through its two high-speed line scan cameras. The sensing cross section is approximately $100 \mathrm{~cm}^{2}$. The imaging grid resolution for raindrops is less than $0.2 \mathrm{~mm}$ in diameter in both horizontal and vertical directions. Each hydrometeor is measured twice through two orthogonally oriented cameras situated in offset measurement planes that are separated by approximately $6 \mathrm{~mm}$ in a vertical direction. The optical alignment and the hydrometeor matching are critical for the accuracy of the measurements. The 2DVD is calibrated by dropping calibration spheres ranging from 0.5 to $10 \mathrm{~mm}$ in diameter. The raw output includes the time stamp, equivalent diameter, measured fall velocity, oblateness, and height, width, and position of the hydrometeor at each plane. Among other disdrometers, the 2DVD provides the most detailed information about the individual hydrometeors and the 2DVD data viewer menu presents the image of the hydrometeors in two measuring planes. Schönhuber et al. (2007) summarized all the technical improvements of the 2DVD until its publication and more detailed information can be found on the manufacturer's (Joanneum Research in Graz, Austria) website (www.distrometer.at).

To improve data quality beyond what the manufacturer's software provides, drops exceeding $\pm 50 \%$ of their theoretical terminal fall speed (Beard 1976) were considered either secondary (i.e., a result of splash) or mismatched drops and eliminated from the dataset, 
which resulted in an elimination of $8 \%$ of the observations. Whereas observations obtained with the firstgeneration 2DVD during TRMM field campaigns in central Florida and the Amazon basin of Brazil, 18\% and $22 \%$ of the observations, respectively, were eliminated after applying the same quality-control method. Thus the faster cameras and new design reduced the production of secondary and mismatched drops.

\section{c. PARSIVEL disdrometer}

The PD is a laser optical disdrometer and was constructed by PM Tech AG, Pfinztal, Germany. The PM Tech sold the right of the PD to OTT Hydromet, Kempten, Germany, after four years of operation in 2004 (M. Löffler-Mang 2007, personal communication). OTT Hydromet improved the calibration of the disdrometer but used a more inexpensive laser device to reduce the cost substantially. Indeed, since it started its production, OTT Hydromet has sold approximately 1000 PD units (K. Nemeth, OTT, 2011, personal communication), many of which are used as present weather sensors.

The PD measures the size and fall velocity of the hydrometeors (Löffler-Mang and Joss 2000). The raw output is the number of drops in 32 size and 32 fall velocity categories. The size and fall velocity ranges are from 0.2 to $25 \mathrm{~mm}$ and from 0.2 to $20 \mathrm{~m} \mathrm{~s}^{-1}$, respectively. The first two size categories, which correspond to sizes less than $0.2 \mathrm{~mm}$, have been left empty because of the low signal-to-noise ratio. The OTT PD laser beam is $180 \mathrm{~mm}$ long, $30 \mathrm{~mm}$ wide, and $1 \mathrm{~mm}$ thick. The nominal cross-sectional area is $54 \mathrm{~cm}^{2}$, but the effective sampling cross section including the edge effects is expressed as $180 \times(30-L / 2)$, where $L$ is the size parameter. The raindrops are approximately spherical for sizes less than $1 \mathrm{~mm}$ in diameter, and therefore the size parameter is the equivalent diameter for raindrops below this size. For larger raindrops, a correction for oblateness has been made to the measured size parameter. The PD measures the fall velocity by monitoring the duration of the hydrometeor presence in its laser beam. A correction has been applied to the fall velocity for size parameters between 1 and $5 \mathrm{~mm}$ (M. Löffler-Mang and U. Blahak 2005, personal communication). Battaglia et al. (2010) presented the measurement principals and accuracies of the PD size and fall velocity measurements for snowflakes. The PD data output is provided either at 10-s or 1-min intervals.

In addition to the data processing discussed above, which was conducted internally by the manufacturer's software, and to be consistent with the 2DVD observations, we removed drops from our PD dataset that exceeded $\pm 50 \%$ of their theoretical terminal fall speed (Beard 1976). This criterion eliminated 20\% of the drops.

\section{Rainfall statistics}

The percent bias and absolute percent bias are used to evaluate the performance of rain gauges and disdrometers. The percent bias and absolute bias between the two instrument measurements $(x, y)$ for $n$ samples are calculated as

$$
\begin{aligned}
\text { percent bias } & =\frac{\text { bias }}{\langle x, y\rangle}, \text { and } \\
\text { percent absolute bias } & =\frac{\text { absolute bias }}{\langle x, y\rangle},
\end{aligned}
$$

where bias, absolute bias, and the mean value between the two variables $\langle x, y\rangle$ are expressed as follows:

$$
\begin{aligned}
\text { bias } & =\frac{1}{n} \sum_{i=1}^{n}\left(x_{i}-y_{i}\right), \\
\text { absolute bias } & =\frac{1}{n} \sum_{i=1}^{n}\left|x_{i}-y_{i}\right|, \quad \text { and } \\
\langle x, y\rangle & =\frac{1}{n} \sum_{i=1}^{n} \frac{\left(x_{i}+y_{i}\right)}{2} .
\end{aligned}
$$

\section{Measurement site and data}

A rain-measuring instrument test site was constructed in Huntsville, Alabama $\left(34.72^{\circ} \mathrm{N}, 86.64^{\circ} \mathrm{W}\right)$. This study employs NASA's newly acquired third generation of the 2DVD, a JWD, and an OTT PD (Fig. 1). The field study was between 18 December 2009 and 2 June 2010.

A Texas Electronics (model TR-525I) tipping-bucket (TB) gauge was operated throughout the experiment and three MetOne Inc. tipping-bucket gauges were deployed near the end of the field study. One of the MetOne gauges malfunctioned as a result of low battery in the datalogger system while the other two MetOne gauges exhibited excellent agreement with $0.4 \%$ bias and $1 \%$ absolute bias for the 22 rain events (Fig. 2a). The agreement between the two MetOne gauges and the Texas Electronics gauges was very good with $5 \%$ bias and $8 \%$ absolute bias between the gauge types (Figs. $2 \mathrm{~b}, \mathrm{c}$ ). Because it was located at the site the longest, the Texas Electronics gauge was considered the reference gauge for evaluating the disdrometers performance. The site was also equipped with an anemometer situated on a $10-\mathrm{m}$ tower, which allowed us to investigate the wind effect on size and fall velocity of raindrops.

\section{Rainfall measurements}

Throughout the field study, the 2DVD recorded $374 \mathrm{~mm}$ of rainfall in 7054 rainy minutes over 32 rain events. A 

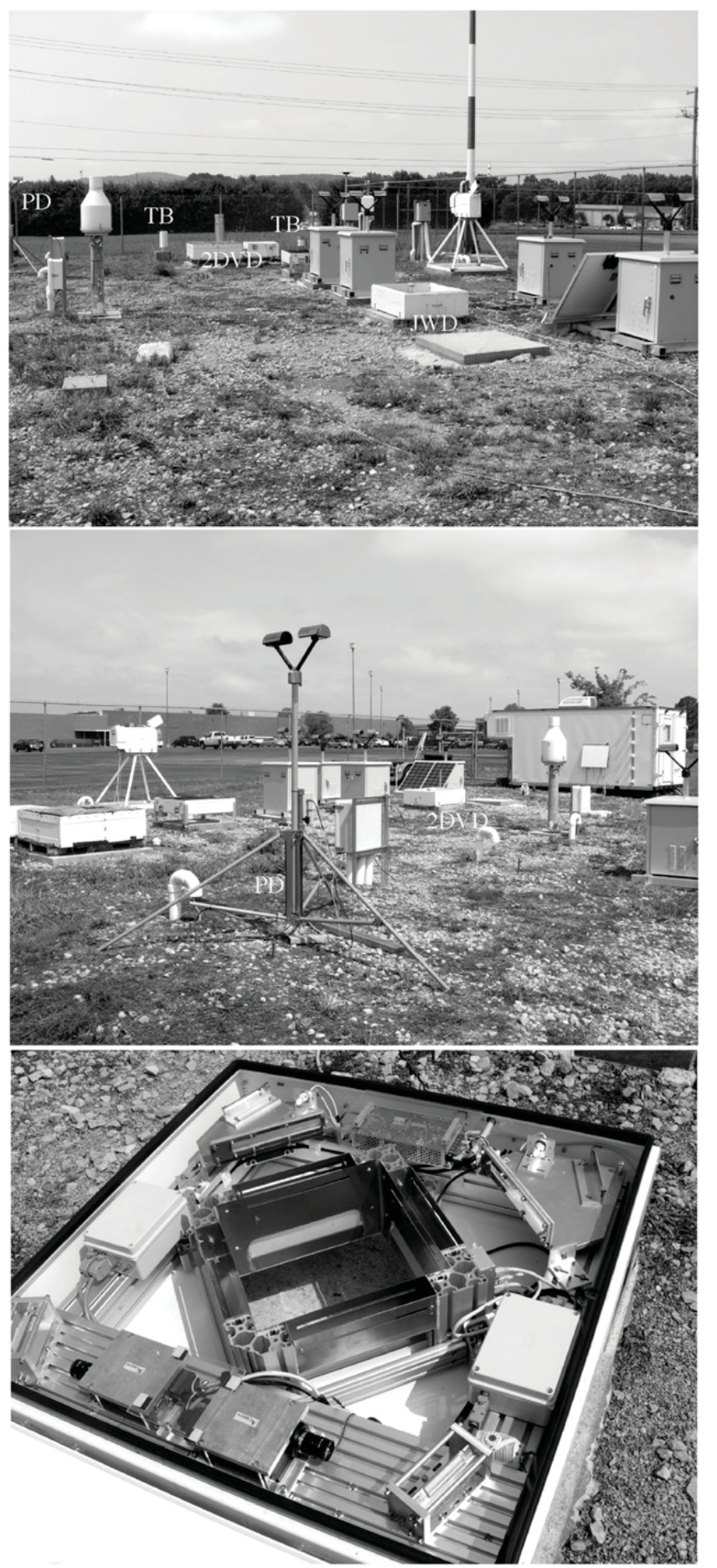

FIG. 1. In situ precipitation measuring test site. The instruments used in this study are labeled as (top) JWD sensor inside the white painted box, TB rain gauge back to the right and one of the secondary TB gauges back to the left; (top),(middle) 2DVD in the back, and PD on the left and in front, respectively. (bottom) A close look at the third generation of 2DVD.

rain event is defined here as having at least $1 \mathrm{~mm}$ of rain accumulation and individual events were segmented by $1 \mathrm{~h}$ or more rain-free periods. A rainy minute must have at least 10 drops and a rain rate of $0.1 \mathrm{~mm} \mathrm{~h}^{-1}$ or higher, similar to the quality control performed by Tokay et al. (2005) on JWD datasets. Integrated over all events, the 2DVD recorded only $0.4 \%$ more rainfall than the rain gauge, which recorded $372 \mathrm{~mm}$ of rainfall. The JWD and $\mathrm{PD}$, on the other hand, had $3.5 \%$ less and $7.5 \%$ more rainfall than the gauge, respectively. The JWD and PD also had 143 more and 117 less rainy minutes than the 2DVD, respectively. This resulted in higher conditional rain rate $\left(3.5 \mathrm{~mm} \mathrm{~h}^{-1}\right)$ for the $\mathrm{PD}$ and lower conditional rain rate $\left(3.0 \mathrm{~mm} \mathrm{~h}^{-1}\right)$ for the JWD. The conditional rain rate is calculated here as the ratio of total accumulation to the rainy minutes.

The JWD accumulated more rainfall than the gauge when the gauge event rain total was less than $6 \mathrm{~mm}$ and vice versa for higher rain totals (Fig. 3a). Higher rain total events in gauge data are usually associated with the occurrence of heavy rain events where the JWD's dead time can result in underestimation of rainfall (Tokay et al. 2005). An empirical dead time correction can be used to increase the JWD estimate of rainfall, but it was not used in this study since it is a multiplicative matrix and therefore does not add any drops when the size bin is empty resulting in an unrealistic size distribution. The 2DVD also accumulated more rainfall than the gauge when the event rain total was less than $5 \mathrm{~mm}$; however, there is very little disagreement between the two at higher rain totals (Fig. 3b). This indicates that the gauge may have underestimated in some events. A single tip of the bucket can have a more pronounced effect on gauge totals at light rainfall, and a partially full bucket that has not tipped may explain some of the event rain total differences. Unlike the 2DVD and JWD, PD had higher accumulations than the gauge in the majority of rain events (Fig. 3c). Among the three disdrometers, the 2DVD showed the best agreement with the rain gauge having the lowest relative and absolute biases. The PD, on the other hand, exhibited the highest biases and absolute biases relative to the gauge, but the absolute bias was still less than $15 \%$, which has been considered an upper threshold by the JWD manufacturer. The JWD and 2DVD exhibited the best agreement among the disdrometers (Fig. 3d), and JWD and PD differed the most in event rain totals (Fig. 3e).

\section{Raindrop size distribution measurements}

As a preface to comparing specific characteristics of the rain DSD between the disdrometers, it is important to note that the agreement between disdrometer event rain totals suggests that their respective measurements of drop numbers in the midsize range are in general agreement; this is because rainfall is mostly contributed 

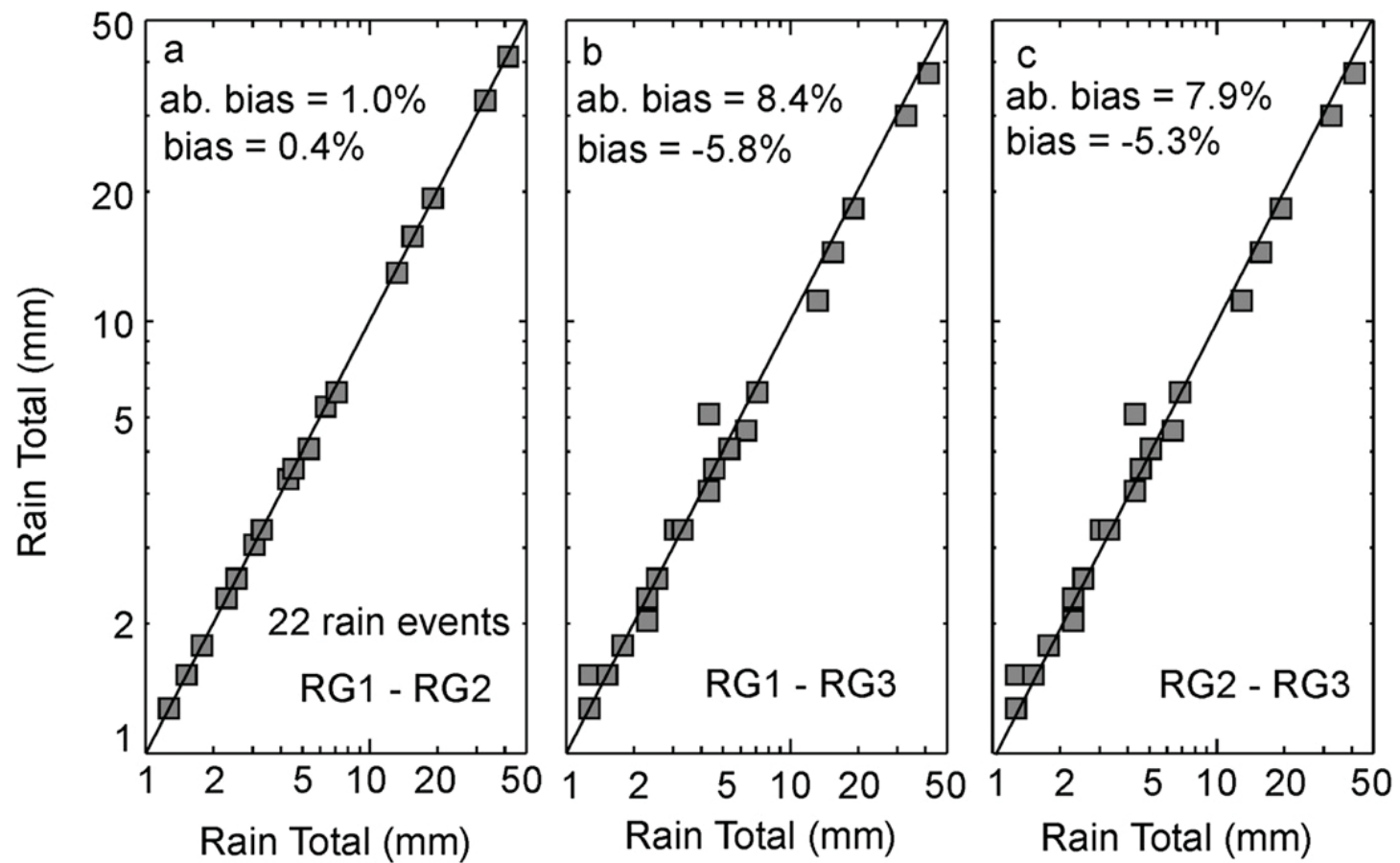

FIG. 2. Comparison of event rain totals between two MetOne Inc. (RG1 and RG2) and the Texas Electronics (RG3) rain gauges for 22 rain events. The percent bias and absolute bias are also given.

by the midsize raindrops. Now in order to more closely examine departures in DSD agreement among the instruments, we move away from rainfall accumulations and focus on 1-min DSD observations averaged to 1-h intervals. Accordingly, we have selected $70 \mathrm{~h}$ of rainfall where all three disdrometers had more than 10 rainy minutes of observations and no more than 3-min differences were observed by all disdrometers to avoid the sampling fluctuations. The maximum drop diameter was also required to exceed $3.5 \mathrm{~mm}$ in all disdrometer hourly spectra to ensure that large drops were adequately sampled. Figure 4 shows 24-hourly composite spectra from 15 different rain events.

Previous observations between 2DVD and JWD from shorter field studies showed that the disagreement between the two disdrometer measurements occur at small and large drops (Tokay et al. 2001, 2002). The concave downward shape of JWD size spectra at the smaller drop end was interpreted as a physical fact as well as an instrument artifact. It was considered that evaporation exceeds collision breakup in convective rain resulting in a concave downward shape of the size spectra as shown in western tropical Africa (Sauvageot and Lacaux 1995) and the western tropical Pacific Ocean (Atlas and Ulbrich 2000). The background noise and disdrometer dead time in the JWD measurements were also attributed to the lack of small drops (Tokay et al. 2003, 2005; Tokay and Bashor 2010).
In this study, the concentration increased toward smaller sizes, and peak concentration occurred in either of the first two size bins (centered at 0.35 and $0.45 \mathrm{~mm}$ ) of the JWD in the majority of the hourly spectra (Fig. 4). At the same time, $14 \%$ of the observations had a peak concentration at $0.651 \mathrm{~mm}$, but these observations did not necessarily coincide with the high rain rates. This shows that the background noise rather than dead time may cause the underestimation of small drops. For 2DVD, the peak concentration was mainly at $0.7 \mathrm{~mm}$ but also observed at $0.3,0.5$, and $0.9 \mathrm{~mm}$ in diameter. The PD had its peak concentration at 0.84 and $0.96 \mathrm{~mm}$. This demonstrated that JWD was more sensitive to the small drops, and PD is the least sensitive. In a few spectra, the increase in concentration toward smaller diameters was not continuous in the JWD data (Figs. $4 \mathrm{t}, \mathrm{u})$. The concentrations were about the same at 0.76 and $0.9 \mathrm{~mm}$ for JWD. It should be noted that the JWD was originally developed to calculate reflectivity, which is proportional to the sixth moment of drop diameter (Joss and Waldvogel 1967). The concentration of small drops has a pronounced effect on total concentration and therefore on the modeling aspect of the DSD.

The sampling cross section of the 2DVD is approximately twice as large as the JWD and PD, and therefore it is expected that the 2DVD may sample the very large drops (larger than $5 \mathrm{~mm}$ in diameter) better than the other two disdrometers. The largest size bin of the JWD 

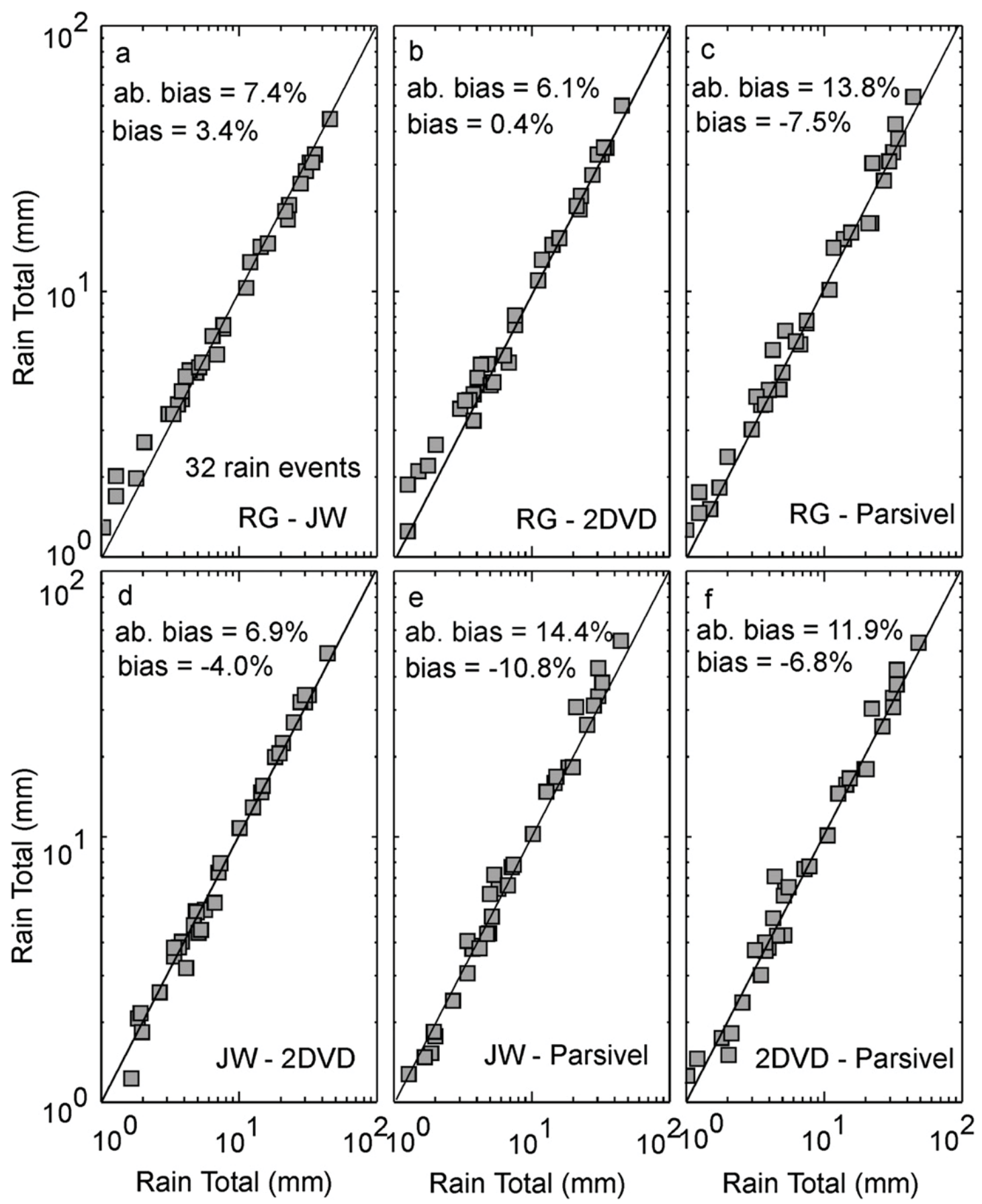

FIG. 3. Comparison of event rain totals between rain gauge, JWD, 2DVD, and OTT PD for 32 rain events. The bias and absolute bias are also given.

is centered at $5.14 \mathrm{~mm}$, and drops of this size and larger are registered in this size bin. Since the JWD size measurement depends on the force at which drops impact the measurement cone and the drop fall velocities only incrementally increase at these very large drops, the JWD cannot distinguish the very large drops. The sampled maximum drop diameter is generally quite different between the disdrometers because of sampling limitations. Fortunately, the very large drops occur quite rarely, and as a result these drops typically do not contribute significantly to the rainfall parameters, except for reflectivity. Yet, the integral rain and DSD parameters that are calculated from model spectra do require the knowledge of maximum drop diameter. The largest drop diameter ever reported in the literature is $8 \mathrm{~mm}$ in diameter, which was observed below 

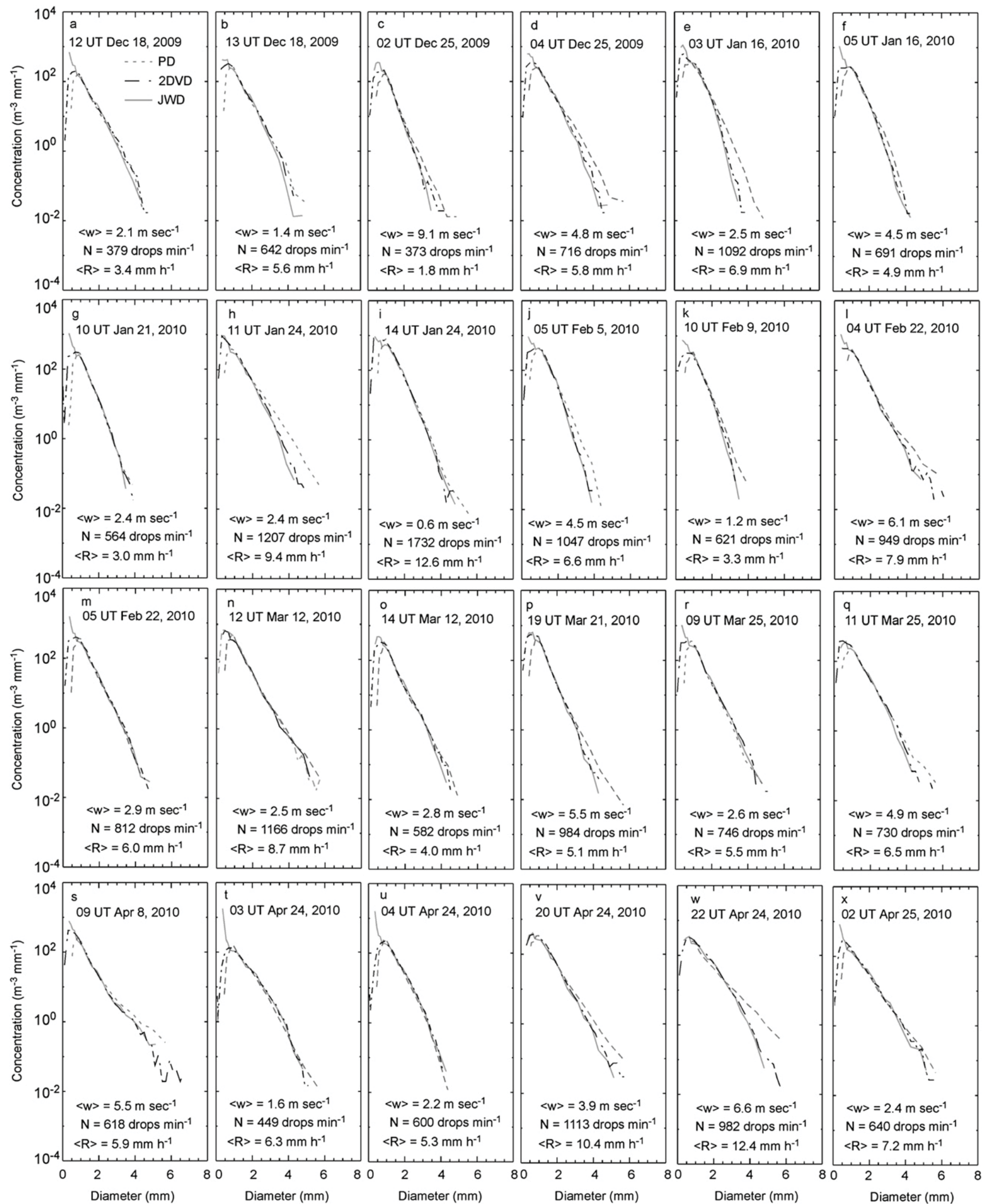

FIG. 4. Comparison of hourly raindrop spectra from selected rain events. The hourly spectra are given for JWD (solid), 2DVD (dasheddotted), and OTT PD (dashed). The hourly wind speed, total number drops $\mathrm{min}^{-1}$, and rain rate are also given. 

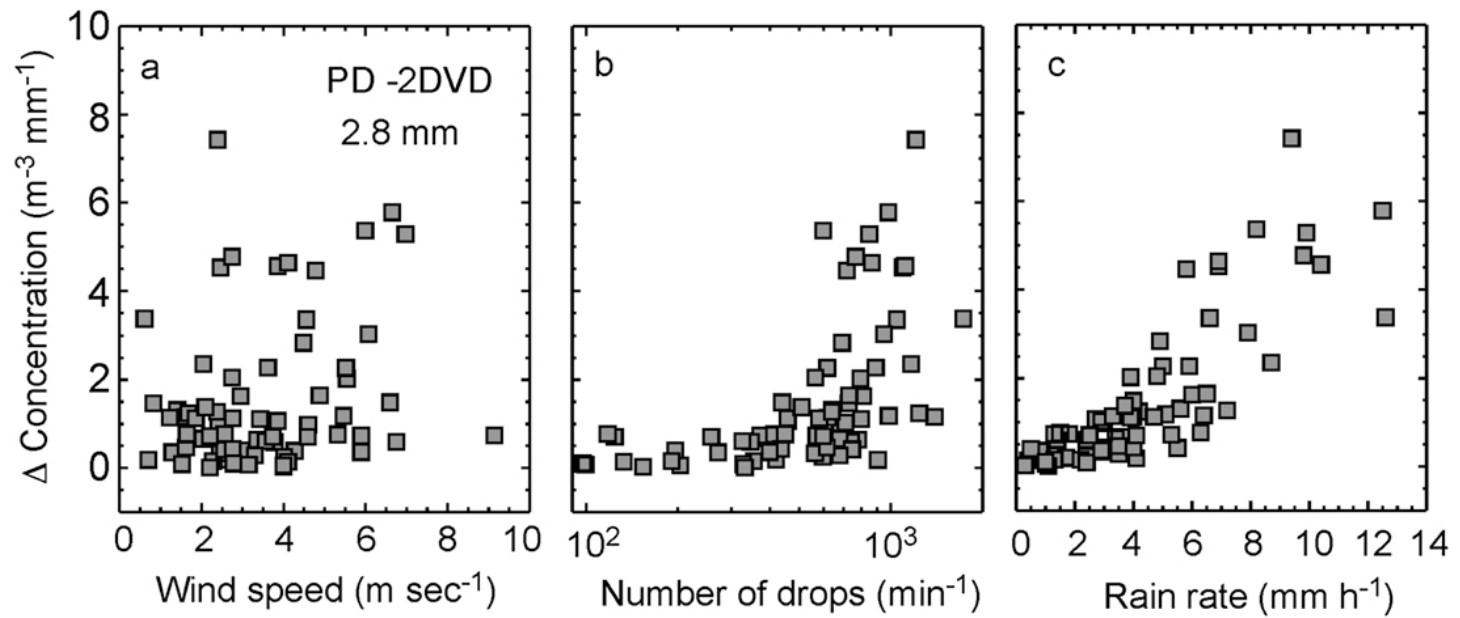

FIG. 5. The difference between OTT PD and 2DVD hourly number concentration at $2.8 \mathrm{~mm}$ in diameter as a function of (a) hourly wind speed, (b) hourly total of drops $\mathrm{min}^{-1}$, and (c) hourly rain rate.

the cloud base using aircraft-mounted particle probes (Beard et al. 1986).

The maximum drop diameter in this study was $7.74 \mathrm{~mm}$ in diameter, which was observed by the 2DVD. Although PD reported a number of drops at its $23 \mathrm{rd}$ size bin, which is centered at $7.72 \mathrm{~mm}$ in diameter, the accuracy of size measurements is questioned and explained later in this section. The PD also had the largest drop sizes in most of the hourly composites. The 2DVD recorded the largest drops in $30 \%$ of the hourly size spectra. The largest drops were larger than the JWD maximum drop diameter limit in $24 \%$ and $34 \%$ of the hourly composites in the 2DVD and PD, respectively. It should be noted that PD bin width is $1 \mathrm{~mm}$ at sizes between 5 and $10 \mathrm{~mm}$ in diameter, and this makes the uncertainty quite high at these sizes.

The most striking feature among hourly composites was the relatively higher concentrations of drops larger than $2.4 \mathrm{~mm}$ in diameter in PD DSDs. This feature was visually observed in numerous composites (Figs. 4d,f,j,w) and cannot be attributed to inadequate sampling. Agreement between the 2DVD and JWD midsize concentrations suggest that the PD overestimates drops larger than $2.4 \mathrm{~mm}$ in diameter in some cases. This feature was not observed when the PM Tech PD was compared with JWD at the NASA Wallops Flight Facility (WFF), Wallops Island, Virginia. This difference may be because OTT used a less expensive laser device, which is approximately $20 \%$ inhomogeneous across the beam (K. Nemeth, OTT, 2010 personal communication). As far as an overestimation of large drops by the PD, Thurai et al. (2011) first reported this problem from a comparison of dual-2DVD and dualPD mass-weighted drop diameters $D_{\text {mass }}$ at a 1-min resolution. They found that PD had a higher $D_{\text {mass }}$ than the 2DVD when $D_{\text {mass }}$ was larger than $2 \mathrm{~mm}$ and the rain rate exceeded approximately $20 \mathrm{~mm} \mathrm{~h}^{-1}$.
In this study, we used a much larger dataset from the same site. Rather than $D_{\text {mass }}$, the difference in concentration between PD and 2DVD at $2.8 \mathrm{~mm}$ was examined as a function of wind speed, drop counts, and rain rate. Figure 5a shows that there is no wind speed dependency, while Figs. $5 b$ and $5 c$ indicate a dependency on the number of drops and rain rate. If the concentration difference of $1 \mathrm{drop} \mathrm{m}^{-3} \mathrm{~mm}^{-1}$ and greater is considered to be significant at this size, the disdrometer observations can be categorized three ways based on drop counts and rain rate. If the drop counts are less than 400 per rainy minute, the concentration difference is insignificant and vice versa is true at drops counts larger than 1000 per rainy minute. Similarly, the concentration difference is insignificant at rain rates less $2.5 \mathrm{~mm} \mathrm{~h}^{-1}$ and is significant at rain rates above $4.5 \mathrm{~mm} \mathrm{~h}^{-1}$. It should be noted that hourly rain rates in Fig. $5 \mathrm{c}$ were calculated from only rainy minutes. Since more drops hit the sampling cross section during more intense rainfall, it is likely that a greater number of drops are subject to fall through the nonuniform cross section of the PD laser, thereby providing a greater chance for large drops to be falsely reported.

\section{Fall velocity measurements}

In addition to the drop size, the 2DVD and PD measures the fall velocity of hydrometeors. After binning the 2DVD size measurements using PD-size bins, the mean and standard deviation of the raindrop fall velocities were calculated for each size bin for 12 rain events. These fall velocity calculations are shown against the interpolated terminal fall speed of raindrops (Beard 1976) in Fig. 6. Each size bin was required to have at least 10 drops in 

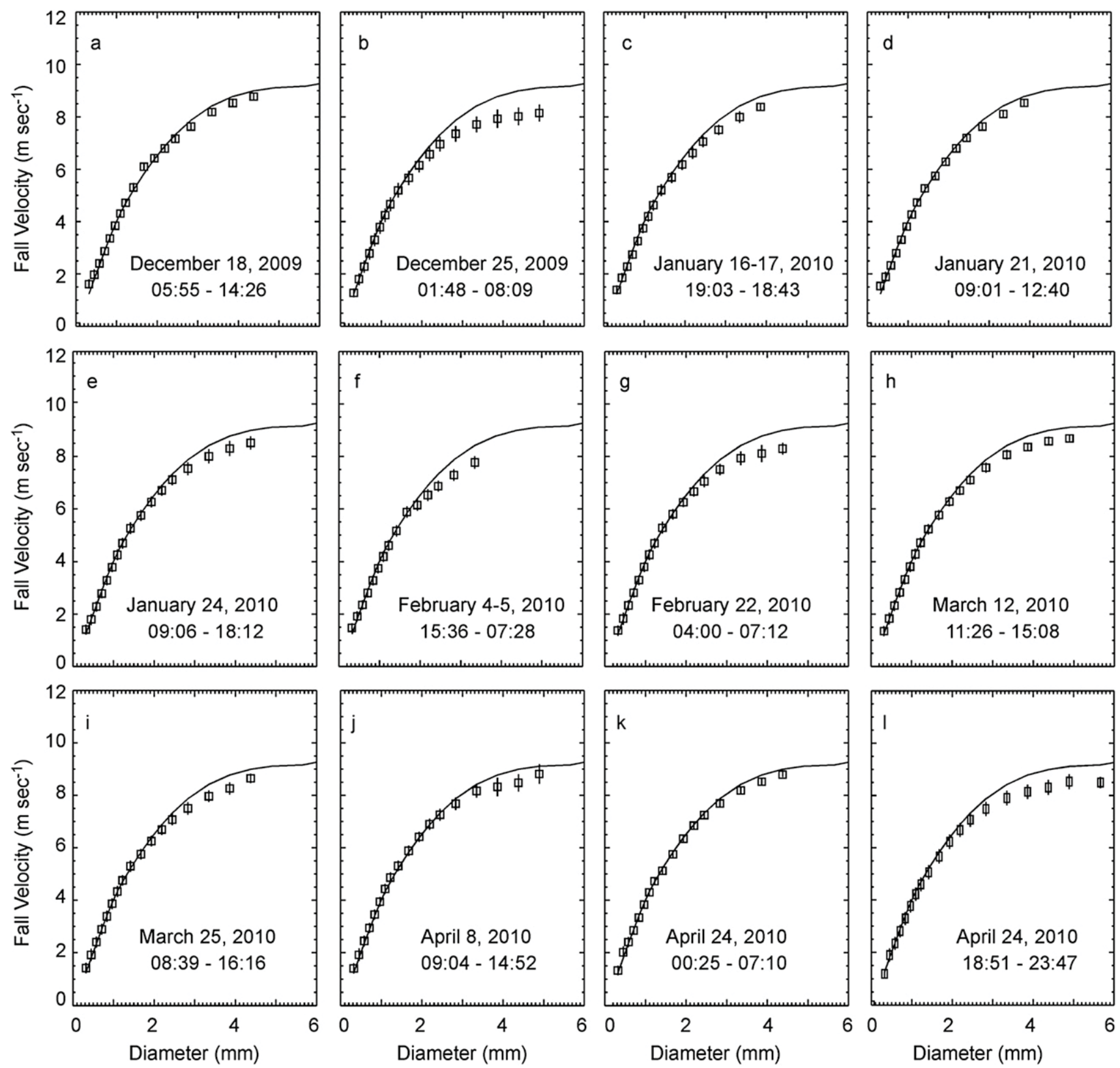

FIG. 6. Mean (squares) and standard deviation (vertical bars) of measured fall velocity by 2DVD as a function of diameter for 12 rain events. The drop counts are binned following OTT PD bin intervals. The terminal fall speed is also shown (line).

a given event. The mean measured fall velocities match the terminal fall speed across all size ranges except for sizes above $2.44 \mathrm{~mm}$ in diameter, where the mean fall velocity was less than the terminal fall speed. The differences between the two fall velocities are apparent in several events (Figs. 6b,f-h). Figure 7 shows the differences in fall velocities in relation to the mean event horizontal wind speed estimated from a collocated anemometer. For a 3.35-mm drop, the terminal fall speed is $8.4 \mathrm{~m} \mathrm{~s}^{-1}$, and three rain events had a $6 \%$ or greater difference in fall speeds when the wind speed exceeded
$4 \mathrm{~m} \mathrm{~s}^{-1}$ (Fig. 7a). At $3.86 \mathrm{~mm}$, the difference was $7 \%$ or higher (Fig. 7b).

The PD fall velocities were higher than the interpolated terminal fall speed at sizes less than $1.22 \mathrm{~mm}$ and vice versa was the case for the larger raindrops with the exception of very large drops, which had higher terminal velocities (Fig. 8). No event-to-event variability was observed. This may indicate that the slower fall velocities in 2DVD DSDs could be related to the measurement error. However, the measurement principles of the 2DVD and PD are different, and the reasoning for 

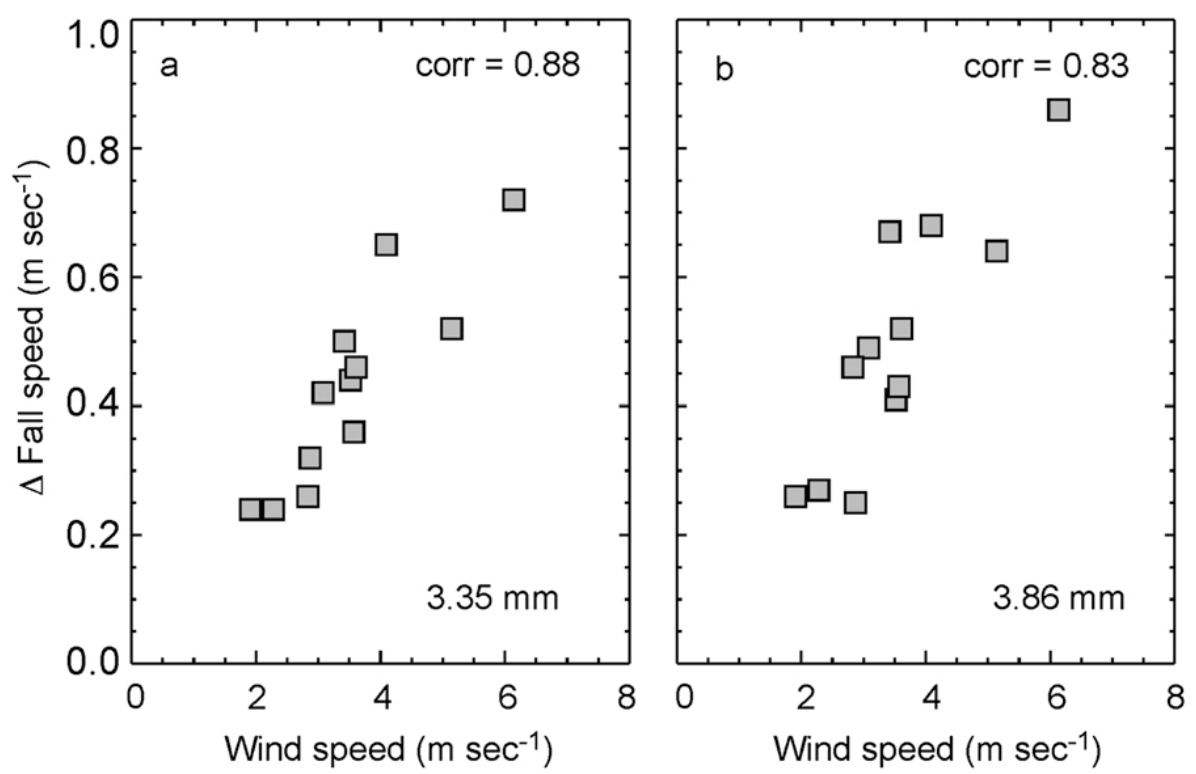

FIG. 7. Differences between terminal fall speed and measured fall velocity of 2DVD as a function of environment wind speed at (a) 3.35 and (b) $3.86 \mathrm{~mm}$ in diameter.

2DVD fall velocity deviation from predicted terminal fall speed is beyond the scope of this study. It should be noted that the OTT PARSIVEL measures fall speeds more accurately than the PM Tech PARSIVEL. PM Tech fall velocities are higher than terminal fall speed at drop sizes less than $0.84 \mathrm{~mm}$ and are less than terminal fall speed at higher sizes as shown from the measurements during the Canadian CloudSat/Cloud-Aerosol Lidar and Infrared Pathfinder Satellite Observations (CALI$P S O)$ Validation Project (C3VP) in Fig. 9. The difference between the fall speeds exceeded $1 \mathrm{~m} \mathrm{~s}^{-1}$ at a diameter of $4.38 \mathrm{~mm}$.

An optical spectrometer developed by Donnadieu (1980) and upgraded by Hauser et al. (1984) also shows the significantly slower fall speeds at sizes larger than $3 \mathrm{~mm}$ (Salles and Creutin 2003). Salles and Creutin (2003) attributed the slower fall speeds to the downdrafts and determined the size measurements errors of the JWD. Krajewski et al. (2006) used an updated model of dual-beam spectrometer and found the agreement with the terminal fall speed was quite good for the drops less than $3 \mathrm{~mm}$ but there were only a few drops at larger sizes. They also found that the PM Tech PARSIVEL had slower drops at sizes above $1.4 \mathrm{~mm}$ in diameter and attributed this feature partly to the quantization of the velocity versus size relationship. The first-generation 2DVD also had slower drops except at small sizes in their study, and this feature was attributed to the wind effect around the bulky structure of the instrument (Nespor et al. 2000). Barthazy et al. (2004) developed a dual-beam hydrometeor velocity and shape detector and found the raindrop fall velocities to be in good agreement with the expected terminal fall speed between 1- and 2.5-mm drops. Drop splash resulted in lower fall speeds at the smaller drop sizes and slightly higher fall speeds were observed for drops larger than $2.5 \mathrm{~mm}$.

\section{Raindrop size distribution and integral rainfall parameters}

As described in the introduction, the three-parameter gamma function is often employed to parameterize the disdrometer-observed DSD measurements in various applications including precipitation retrieval algorithms from TRMM and GPM radar measurements. In this study, two different normalized gamma functions are employed to determine the role of different disdrometer measurements on DSD. The normalization was done with respect to the total concentration $N_{T}$ and liquid water content $w$ (Tokay and Bashor 2010). The normalized intercept parameters with respect to total concentration $N_{T}^{*}$ and liquid water content $N_{w}$ are expressed as

$$
\begin{aligned}
& N_{T}^{*}=\frac{N_{T}}{D_{\text {mass }}} \text { and } \\
& N_{w}=\frac{256}{\pi \rho_{w}} \frac{10^{3} W}{D_{\text {mass }}^{4}},
\end{aligned}
$$



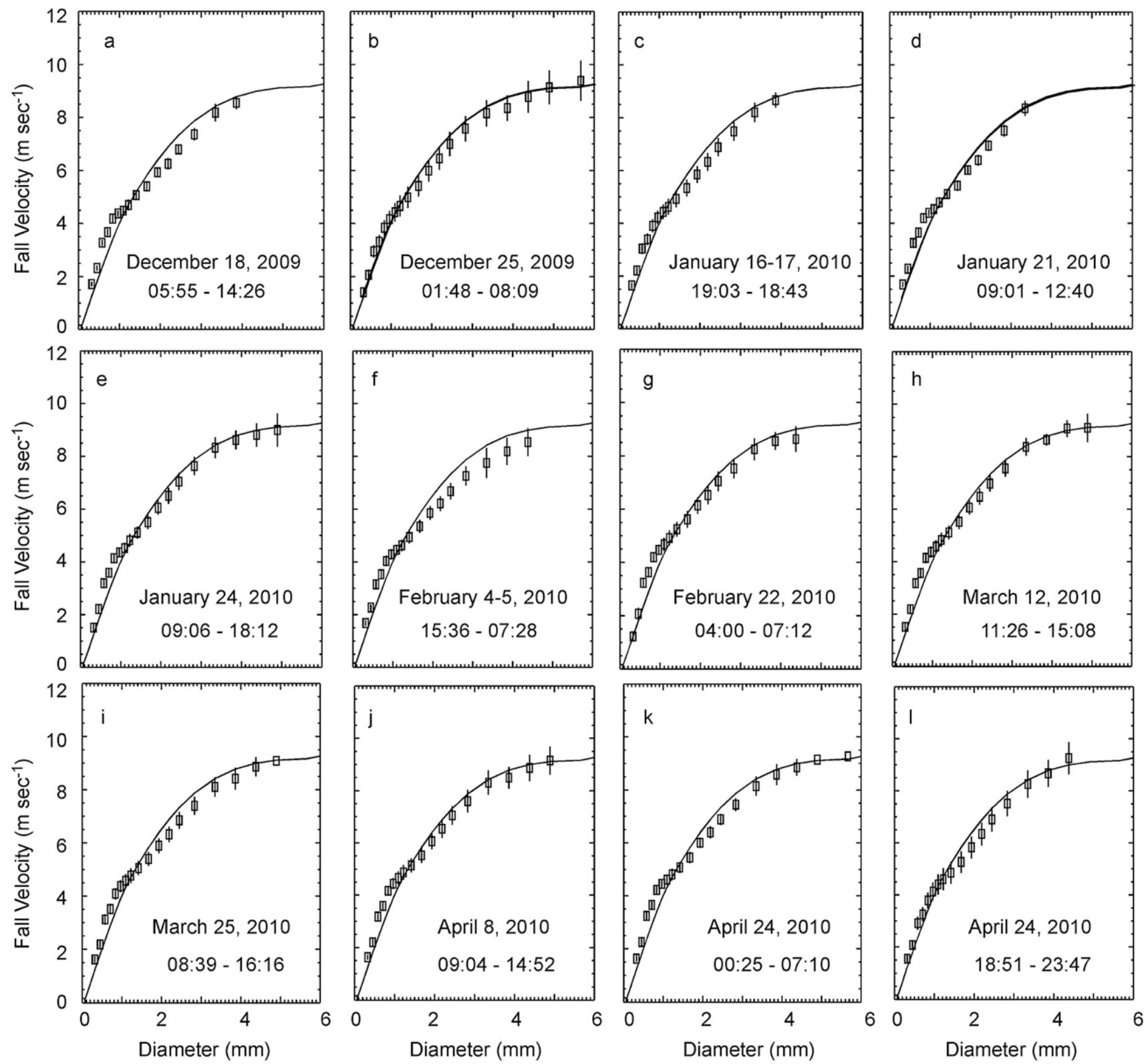

FIG. 8. Mean (squares) and standard deviation (vertical bars) of measured fall velocity by OTT PD as a function of drop diameter for 12 rain events. The terminal fall speed is also shown (line).

where $D_{\text {mass }}$ is the mean mass diameter and $\rho_{w}$ is the density of water. The mean mass diameter is directly calculated from observed DSD and is related to the slope and shape parameters of the gamma distribution as

$$
D_{\text {mass }}=\frac{4+m}{\Lambda} .
$$

The normalized intercept parameters can then be calculated from observed spectra as well. The corresponding normalized gamma-fitted distributions are expressed as

$$
\begin{aligned}
& N(D)=N_{T}^{*} f_{1}(m)\left(\frac{D}{D_{\text {mass }}}\right)^{m} \exp \left[-(4+m) \frac{D}{D_{\text {mass }}}\right] \text { and } \\
& N(D)=N_{w} f_{2}(m)\left(\frac{D}{D_{\text {mass }}}\right)^{m} \exp \left[-(4+m) \frac{D}{D_{\text {mass }}}\right], \\
& \text { where } f_{1}(m) \text { and } f_{2}(m) \text { are given as }
\end{aligned}
$$

$$
f_{1}(m)=\frac{(4+m)^{m+1}}{\Gamma(m+1)} \text { and }
$$




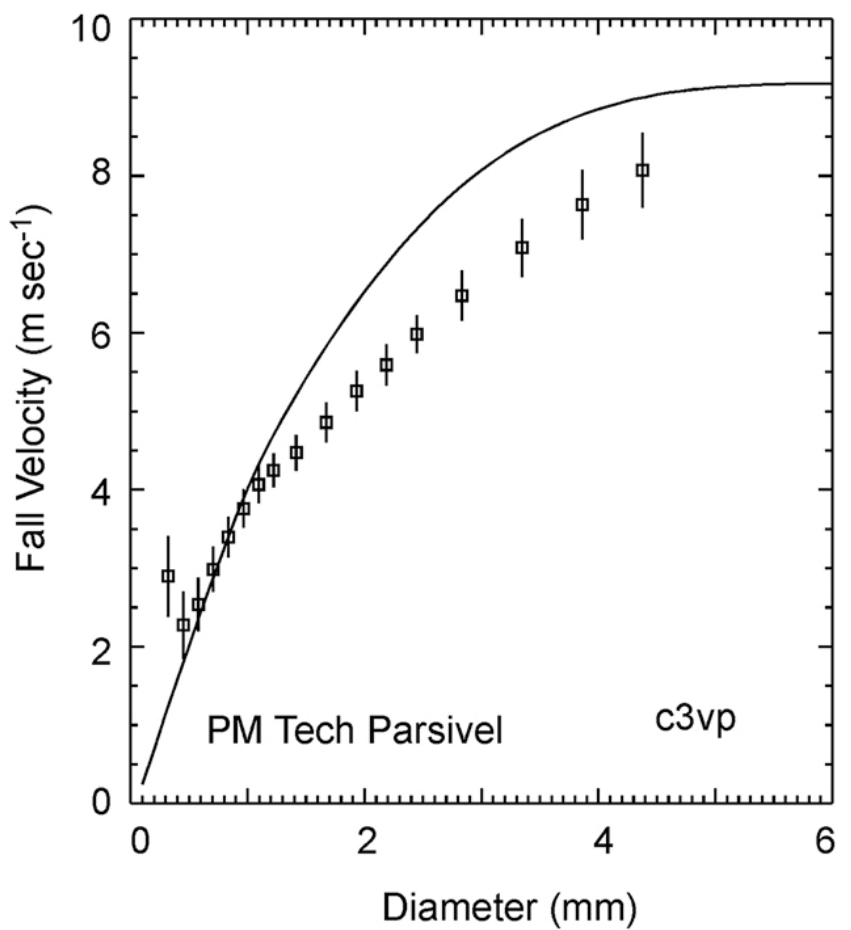

FIG. 9. Mean (squares) and standard deviation (vertical bars) of the fall speed measured by PM Tech PD as a function of drop diameter. The measurements were taken during C3VP and terminal fall speed is also given (line).

$$
f_{2}(m)=\frac{6}{256} \frac{(4+m)^{m+4}}{\Gamma(m+4)} .
$$

The shape parameter is extracted by minimizing the error in rain rates that are calculated from observed spectra and from fitted-gamma distribution in Eqs. (10) and (11). The shape parameters that are derived from Eqs. (10) and (11) differ from each other, and they are denoted as $m_{1}$ and $m_{2}$ for the rest of the study. It should be noted that both Eq. (9) and the rain rate calculated from Eqs. (10) and (11) assume the complete gamma function where the integral over drop diameter is from 0 to infinity. In reality, there is a minimum and maximum drop size in an observed DSD and the incomplete gamma function should be a more realistic fit. The differences in gamma-fitted parameters due to complete and incomplete gamma function have been studied in the past (Ulbrich and Atlas 1998; Vivekanandan et al. 2004) and are beyond the scope of this study.

To determine the measurement accuracy, a subset of 1-min observations was created from JWD and PD observations where at least 100 drops were recorded. At least 50 drops were counted for the subset in 2DVD, which has twice the sampling cross section. The subset had 5349 1-min samples for all DSD and rain parameters except for the shape parameter. The range of shape parameters may be considered to fall between -2 and 20 even though higher values are occasionally reported (Tokay and Short 1996). Approximately 7\% of the data was disregarded because it was outside this range. The out-of-range values of the shape parameters are partly due to the use of complete gamma function and partly because the gamma fit is not well suited to the observed DSD.

Four statistics [Eqs. (2)-(5)] are listed in Table 1 for three pairs of eight DSD and integral rain parameters. The biases show that PD had the highest values and the JWD had the lowest values for all parameters. Because of the logarithmic values, this may not be clear in $N_{T}^{*}$ and $N_{w}$. The percent bias between PD and the other two disdrometers exceeded $20 \%$, largely a result of PD's overestimation of drops larger than $2.4 \mathrm{~mm}$ in diameter. The bias and absolute bias in reflectivity was 0.9 and $2.0 \mathrm{dBZ}$ between PD and JWD because of the differences in midsize and large drops. The differences between the disdrometer measurements were also noticeable in the mean mass diameter and liquid water content. Consequently, the intercept and shape parameters of the gamma distribution that are based on integral rain and DSD parameters showed noticeable differences. While the significant differences in small drops were the main cause for observed differences in $N_{T}^{*}$, the differences at

TABLE 1. Four different rainfall statistics of the DSD and integral rain parameters between the pairs of disdrometer measurements.

\begin{tabular}{|c|c|c|c|c|c|c|c|c|c|c|c|c|}
\hline & \multicolumn{3}{|c|}{ Bias } & \multicolumn{3}{|c|}{ Absolute bias } & \multicolumn{3}{|c|}{ Bias (\%) } & \multicolumn{3}{|c|}{ Absolute bias (\%) } \\
\hline & $\begin{array}{c}\text { 2DVD, } \\
\text { PD }\end{array}$ & $\begin{array}{l}\text { 2DVD, } \\
\text { JWD }\end{array}$ & $\begin{array}{l}\text { PD, } \\
\text { JWD }\end{array}$ & $\begin{array}{c}\text { 2DVD, } \\
\text { PD }\end{array}$ & $\begin{array}{l}\text { 2DVD, } \\
\text { JWD }\end{array}$ & $\begin{array}{c}\text { PD, } \\
\text { JWD }\end{array}$ & $\begin{array}{c}\text { 2DVD, } \\
\text { PD }\end{array}$ & $\begin{array}{l}\text { 2DVD, } \\
\text { JWD }\end{array}$ & $\begin{array}{l}\text { PD, } \\
\text { JWD }\end{array}$ & $\begin{array}{c}\text { 2DVD, } \\
\text { PD }\end{array}$ & $\begin{array}{l}\text { 2DVD, } \\
\text { JWD }\end{array}$ & $\begin{array}{l}\text { PD, } \\
\text { JWD }\end{array}$ \\
\hline$R\left(\mathrm{~mm} \mathrm{~h}^{-1}\right)$ & -0.31 & 0.17 & 0.48 & 0.91 & 0.73 & 1.09 & -7.5 & 4.5 & 11.9 & 21.6 & 18.5 & 26.6 \\
\hline$Z(\mathrm{~dB} Z)$ & -0.64 & 0.25 & 0.89 & 1.76 & 1.38 & 2.00 & -2.2 & 0.8 & 3.0 & 6.0 & 4.8 & 6.9 \\
\hline$D_{\text {mass }}(\mathrm{mm})$ & -0.09 & 0.03 & 0.13 & 0.13 & 0.09 & 0.16 & -6.7 & 2.7 & 9.4 & 9.7 & 6.6 & 11.8 \\
\hline$w\left(\mathrm{~g} \mathrm{~m}^{-3}\right)$ & -0.001 & 0.006 & 0.008 & 0.036 & 0.033 & 0.044 & -0.7 & 3.0 & 3.7 & 17.5 & 16.3 & 21.3 \\
\hline $10 \log N_{T}^{*}$ & 2.39 & -0.90 & -3.29 & 2.41 & 1.64 & 3.34 & 10.4 & -3.6 & -14.0 & 10.5 & 6.7 & 14.3 \\
\hline $10 \log N_{w}$ & 1.39 & -0.55 & -1.95 & 1.63 & 1.13 & 2.12 & 3.9 & -1.5 & -5.4 & 4.6 & 3.1 & 5.9 \\
\hline$m_{1}$ & -2.51 & 0.44 & 2.95 & 2.81 & 1.69 & 3.41 & -45.2 & 10.7 & 55.3 & 50.4 & 41.4 & 63.9 \\
\hline$m_{2}$ & -0.70 & 0.85 & 1.55 & 2.08 & 1.77 & 2.75 & -13.3 & 19.0 & 32.2 & 39.7 & 39.8 & 57.2 \\
\hline
\end{tabular}


all sizes resulted in significant differences in $m_{1}$ as well. The differences in $N_{w}$ and in $m_{2}$ were relatively less since the differences in the small drop range played a less important role for these parameters. It should be noted that the differences in drop counts at sizes larger than $4.5 \mathrm{~mm}$ in diameter typically do not contribute to the differences in DSD and rain parameters significantly because of their infrequent occurrence in disdrometer observations.

The probability and cumulative distributions of $R, Z$, $w$, and $D_{\text {mass }}$ did not show significant differences between the disdrometer measurements (Figs. 10a-h), but the mean values were noticeably higher in PD and lower in the JWD (Table 2). The difference in the mean values between the these two disdrometers were $0.5 \mathrm{~mm} \mathrm{~h}^{-1}$ in $R, 3 \mathrm{dBZ}$ in Z, $0.008 \mathrm{~g} \mathrm{~m}^{-3}$ in $w$, and $0.13 \mathrm{~mm}$ in $D_{\text {mass. }}$. The mean values in the $2 \mathrm{DVD}$ data were between the other two disdrometers, and the median values were more similar among the three disdrometers.

The probability and cumulative distributions of the intercept and shape parameters showed significant differences between the disdrometer measurements (Figs. 10i-p). The lack of small drops in PD shifted the probability and cumulative distributions of $N_{T}^{*}$ and $N_{w}$ toward smaller values but more so for distributions of $N_{T}^{*}$. The significantly lower mean and median values of $N_{T}^{*}$ and $N_{w}$ in PD were reflected in the probability and cumulative distributions (Figs. 10i,j). The 2DVD also had noticeable differences from the JWD in the probability and cumulative distributions as a result of the lack of small drops in the 2DVD DSDs. The shape parameters had noticeably different probability and cumulative distributions, but the PD distributions exhibited substantially different distributions than the other two disdrometers. The median values of $m_{1}$ and $m_{2}$ were 3.2 and 3.4 in JWD and were very close to the constant value of $m=3$, which is used in the TRMM precipitation algorithm (Kozu et al. 2009a).

To determine the role of the differences in midsize and large drops on probability and cumulative distributions of intercept and shape parameters, these parameters were recalculated after eliminating small drops from the drop size spectra. The agreement between the disdrometers in distributions of $N_{T}^{*}$ and $N_{w}$ was very good, but the distributions were quite different than when the small drops were included (Figs. 11a,b,e,f). The agreement in distributions of $m_{1}$ and $m_{2}$ was also greatly improved when the small drops were eliminated, but there were still noticeable differences (Figs. 11c,d,g,h). The mean and median values of PD were relatively lower than the other disdrometers, and all three resulted in higher shape parameters and lower intercept parameters in the absence of small drops (Table 2).

\section{Conclusions}

This study presented a series of measurement comparisons between JWD, 2DVD, and OTT PARSIVEL. The results of the instrument comparisons can be used to address questions related to disdrometer application and measurement uncertainty. For example, if the requirement is accurate sampling of the entire drop size spectrum, what is the most accurate disdrometer configuration to employ? The answer obtained from this dataset is a combination of the JWD and 2DVD. For the study period examined herein, the JWD performed relatively well at the small drop end, while the 2DVD was able to better distinguish the size of large drops. If the requirement is related to the integral parameters of $w$ and $R$, both the JWD and 2DVD can be advocated since the small drops do not significantly influence these parameters. The contribution of drops larger than $4.5 \mathrm{~mm}$ in diameter on $w$ and $R$ can also be considered insignificant since these drops are typically rare in most DSD observed with disdrometers. For $Z$, the very large drops can play a significant role especially in the presence of low drop counts, which are typically observed at the very early stage of convective rainfall in disdrometer measurement. At the same time, the large drop counts can be significant in a weather radar volume of continental convection having high values of reflectivity. Thus, the significance of large drops on the integral rainfall parameters depends upon the measurement scale.

Concerning fall velocity, the OTT PARSIVEL measurements followed the parametric representation of the GK terminal fall speed of raindrops fairly well, an improvement over previous PM Tech PARSIVEL measurements that exhibited significantly slower fall velocities for drop sizes larger than $1.5 \mathrm{~mm}$ in diameter. The improved fall speed measurements by the OTT PARSIVEL seem to be associated with a more sophisticated calibration procedure. The 2DVD, on the other hand, recorded lower fall velocities than GK-predicted terminal fall speeds for drop sizes exceeding diameters of $2.44 \mathrm{~mm}$ in several events where the mean wind speeds exceeded $4 \mathrm{~m} \mathrm{~s}^{-1}$. The cause of slower fall speeds measured by the 2DVD is a topic for investigation but beyond the scope of this study.

For parametric forms of the DSD, normalized gamma function parameters such as $\mathrm{N}_{\mathrm{W}}$ can be extracted more accurately than those with respect to $N_{T}^{*}$ since the latter is more sensitive to the small drop counts. This is important because the parametric form of the DSD is of great interest for the precipitation retrieval community. The integral parameters derived from the parametric form of DSD require information on the minimum and maximum drop diameters. The minimum drop diameter 

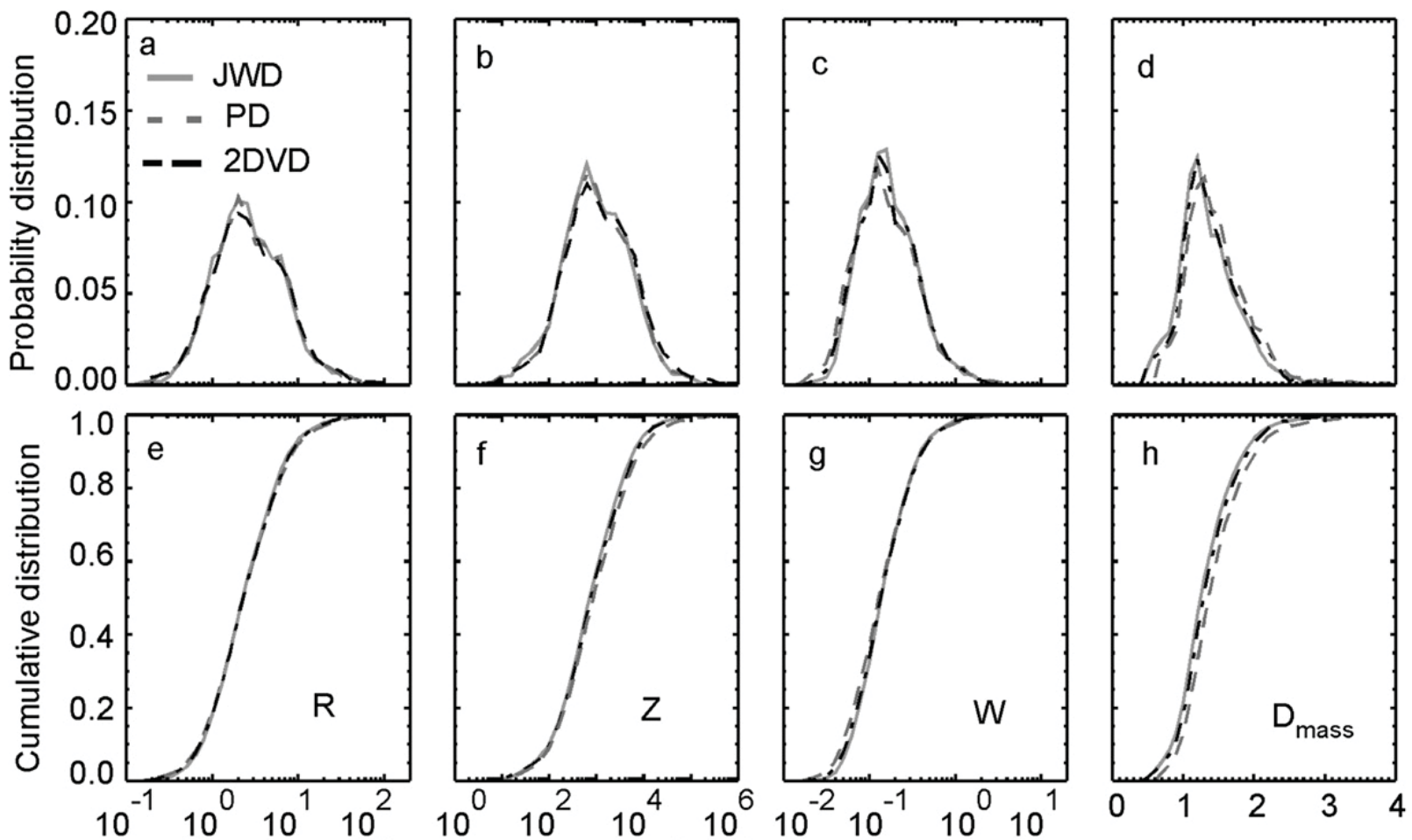

Rain Rate $\left(\mathrm{mm} \mathrm{h}^{-1}\right)$
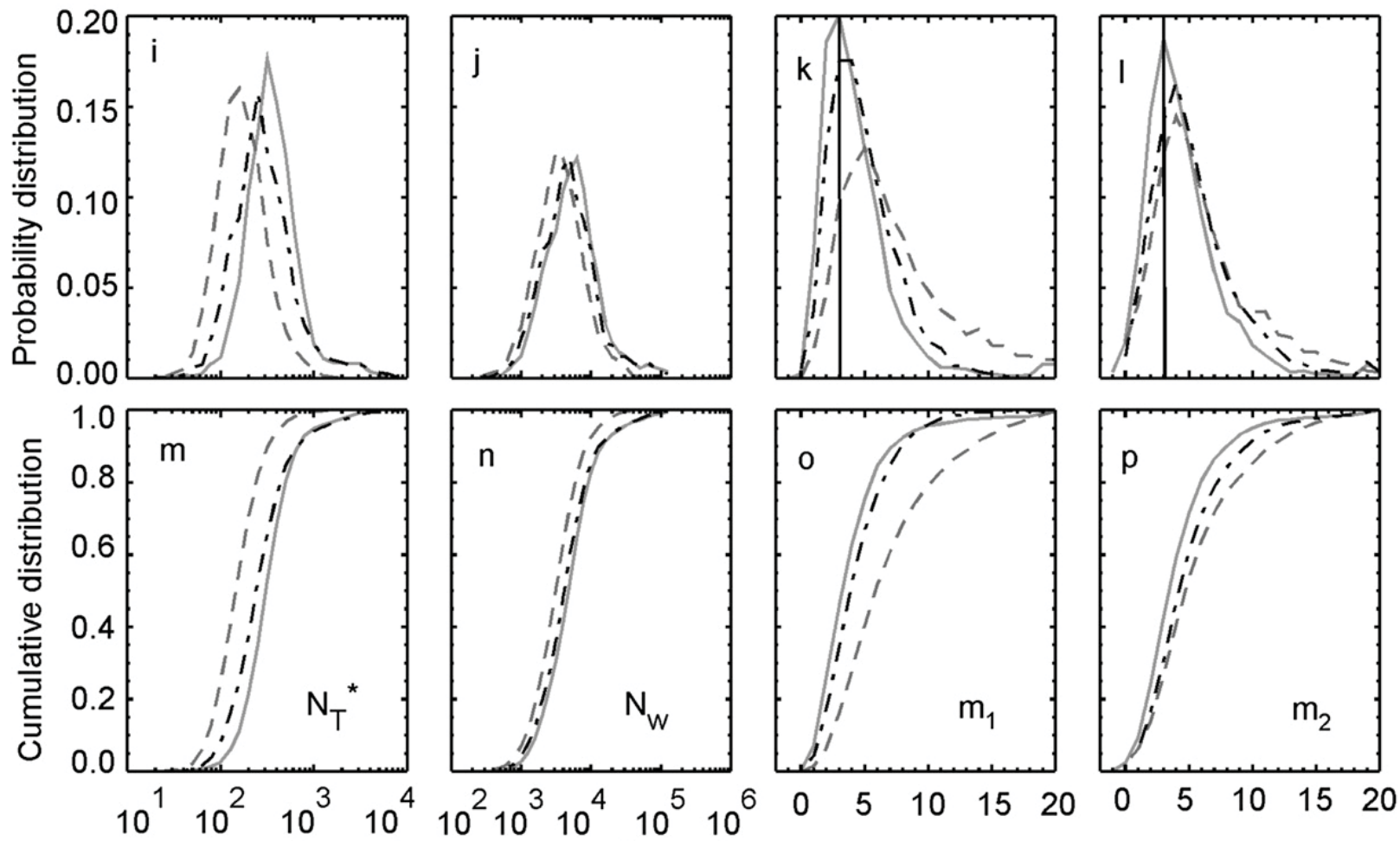

Intercept $\left(\mathrm{m}^{-3} \mathrm{~mm}^{-1}\right)$

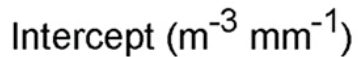

Shape parameter

Shape parameter

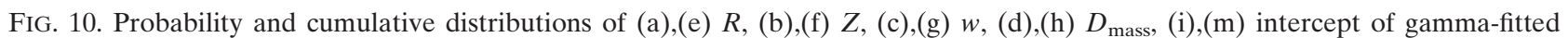
distribution with respect to $N_{T}$ and $D_{\text {mass, }}$, (j),(n) intercept of gamma-fitted distribution with respect to $w$ and $D_{\text {mass, }}$ (k),(o) shape parameter of gamma-fitted distribution with respect to $N_{T}^{*}$, and (l),(p) shape parameter of gamma-fitted distribution with respect to $N_{w}$. The shape parameter of 3, which is used by the TRMM precipitation radar algorithm, is marked in (k) and (l). 
TABLE 2. Mean and median of the distributions of the DSD and integral rain parameters, which are derived from three different disdrometer measurements. The values for raindrop distribution parameters that were recalculated after removal of small drops are marked in boldface.

\begin{tabular}{|c|c|c|c|c|c|c|}
\hline & \multicolumn{3}{|c|}{ Mean } & \multicolumn{3}{|c|}{ Median } \\
\hline & 2DVD & $\mathrm{PD}$ & JWD & 2DVD & PD & JWD \\
\hline$R\left(\mathrm{~mm} \mathrm{~h}^{-1}\right)$ & 4.07 & 4.35 & 3.86 & 2.26 & 2.26 & 2.23 \\
\hline$Z(\mathrm{~dB} Z)$ & 35.3 & 37.72 & 34.76 & 18.76 & 18.53 & 18.57 \\
\hline$w\left(\mathrm{~g} \mathrm{~m}^{-3}\right)$ & 0.208 & 0.210 & 0.202 & 0.135 & 0.128 & 0.136 \\
\hline$D_{\text {mass }}(\mathrm{mm})$ & 1.35 & 1.44 & 1.31 & 1.28 & 1.36 & 1.24 \\
\hline$N_{T}^{*}\left(\mathrm{~m}^{-3} \mathrm{~mm}^{-1}\right)$ & 390 & 181 & 419 & 239 & 145 & 305 \\
\hline$N_{w}\left(\mathrm{~m}^{-3} \mathrm{~mm}^{-1}\right)$ & 7529 & 4355 & 8446 & 4109 & 3115 & 4795 \\
\hline$m_{1}$ & 4.3 & 6.8 & 3.9 & 3.8 & 5.8 & 3.2 \\
\hline$m_{2}$ & 4.9 & 5.6 & 4.1 & 4.2 & 4.6 & 3.4 \\
\hline$N_{T}^{*}\left(\mathrm{~m}^{-3} \mathrm{~mm}^{-1}\right)$ & 67 & 57 & 65 & $\mathbf{5 0}$ & 44 & 51 \\
\hline$N_{w}\left(\mathrm{~m}^{-3} \mathrm{~mm}^{-1}\right)$ & 1770 & 1422 & 1754 & 1307 & 1091 & 1330 \\
\hline$m_{1}$ & 7.9 & 7.1 & 8.6 & 7.8 & 7.2 & 8.7 \\
\hline$m_{2}$ & 10.1 & 9.2 & 10.7 & 9.6 & 8.7 & 10.5 \\
\hline
\end{tabular}

is mainly linked to the disdrometer's ability to measure the smallest drops. At the current stage, it is considered $0.2 \mathrm{~mm}$ for the 2DVD and $0.3 \mathrm{~mm}$ for the JWD. Since the 2DVD severely underestimates the number of drops in the first size bin, $0.3 \mathrm{~mm}$ should be considered the minimum drop diameter. On the other end of the size spectrum, the maximum drop diameter is related to the sampling area of the disdrometer as well as the physics of precipitation. Since a radar volume is much greater than the measurement area of a single disdrometer,
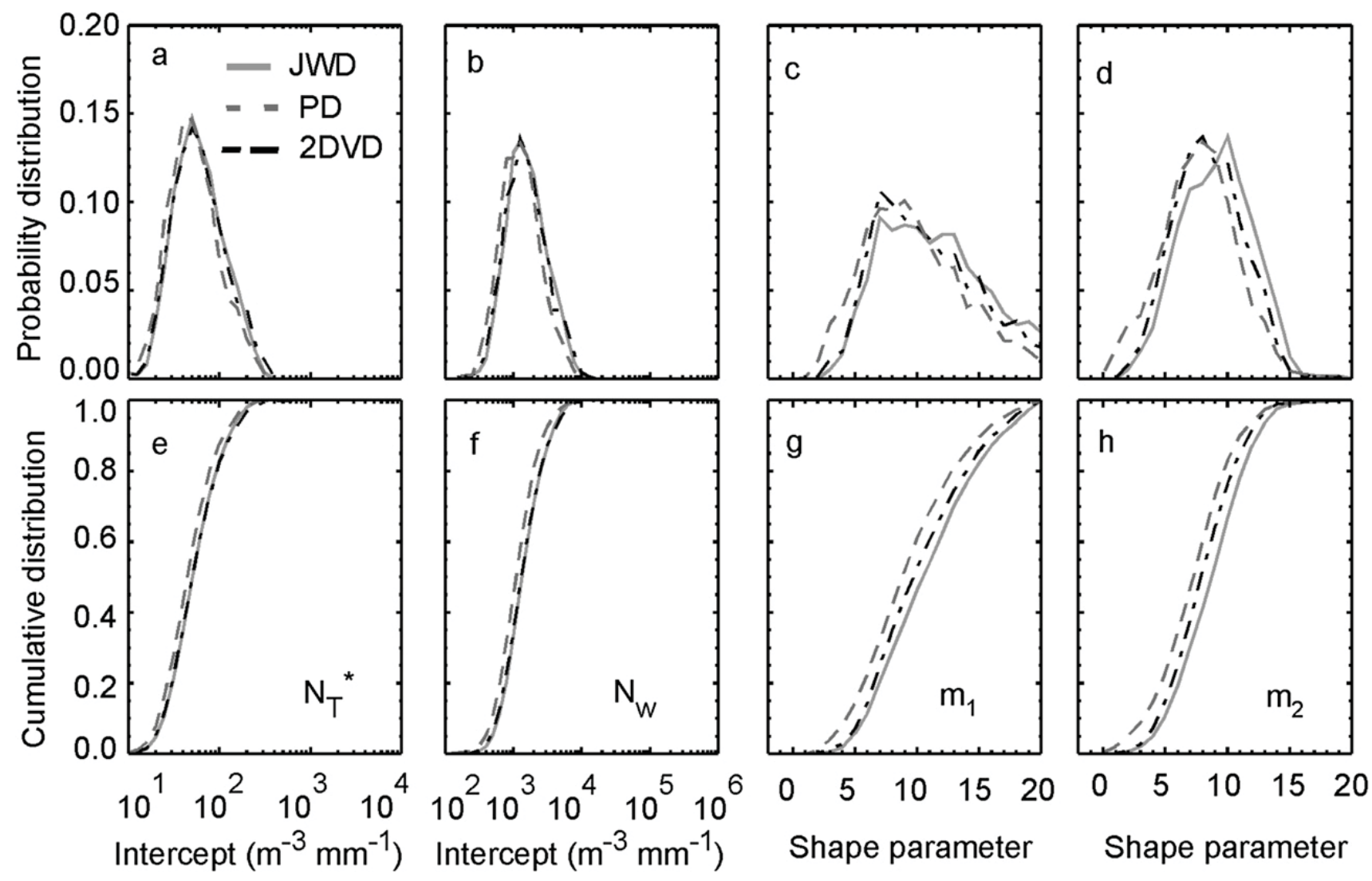

FIG. 11. Probability and cumulative distributions of (a),(e) intercept of gamma-fitted distribution with respect to $N_{T}$ and $D_{\text {mass }}$, (b),(f) intercept of gamma-fitted distribution with respect to $w$ and $D_{\text {mass }},(\mathrm{c}),(\mathrm{g})$ shape parameter of gamma-fitted distribution with respect to $N_{T}^{*}$, and (d),(h) shape parameter of gamma-fitted distribution with respect to $N_{w}$ after eliminating small drops from size spectra. 
long-term observations with clustered or networked 2DVDs are needed to determine the maximum drop diameter and, subsequently, its impact on the retrieval of DSD moments. The GPM ground validation program, which has recently operated five of the thirdgeneration 2DVDs in field campaigns and begun an extended deployment of them at WFF, will be expected to provide information on this matter.

Underestimation of the number of drops less than $0.76 \mathrm{~mm}$ in diameter and overestimation of the drop concentration above $2.4 \mathrm{~mm}$ in diameter are the shortcomings of OTT PARSIVEL. These trends were not observed in the PM Tech PARSIVEL. This apparent limitation of the OTT PARSIVEL tended to occur when mean hourly rain rates exceeded $2.5 \mathrm{~mm} \mathrm{~h}^{-1}$ and the total number of drops were greater than 400 in a sampled minute but no dependence on environmental wind speed was found in this study. Therefore, the observed measurement bias is attributed to the partially inhomogeneous laser beam of the OTT PARSIVEL. The manufacturer released an upgraded version of the OTT PARSIVEL (PARSIVEL ${ }^{2}$ ) where the laser beam is expected to be homogeneous. An evaluation of PARSIVEL $^{2}$ is underway and is expected to perform better at all size ranges.

Acknowledgments. Feedback from the manufacturers of Joss-Waldvogel, OTT PARSIVEL, and the twodimensional video disdrometers are greatly appreciated. Acknowledgements extended to the three anonymous reviewers for their constructive comments. This study was funded under NASA's Global Precipitation Measurement mission via Arthur Hou (GPM Project Scientist) and Mathew Schwaller (GPM Ground Validation Project Manager) of NASA Goddard Space Flight Center, and NASA's Precipitation Measurement Mission (PMM) Grants NNX07AF45G and NNX10AJ12G, managed by Ramesh Kakar of NASA Headquarters, Program Scientist.

\section{REFERENCES}

Atlas, D., and C. W. Ulbrich, 2000: An observationally based conceptual model of warm oceanic convective rain in the tropics. J. Appl. Meteor., 39, 2165-2181.

$\longrightarrow,-$ _ F. D. Marks Jr., E. Amitai, and C. R. Williams, 1999: Systematic variation of drop size and radar-rainfall relations. J. Geophys. Res., 104 (D6), 6155-6169.

Barthazy, E., S. Göke, R. Schefold, and D. Högl, 2004: An optical array instrument for shape and fall velocity measurements of hydrometeors. J. Atmos. Oceanic Technol., 21, 1400-1416.

Battaglia, A., E. Rustemeier, A. Tokay, U. Blahak, and C. Simmer, 2010: PARSIVEL snow observations: A critical assessment. J. Atmos. Oceanic Technol., 27, 333-344.

Beard, K. V., 1976: Terminal velocity and shape of cloud and precipitation drops aloft. J. Atmos. Sci., 33, 851-864.
— D. B. Johnson, and D. Baumgardner, 1986: Aircraft observations of large raindrops in warm, shallow, convective clouds. Geophys. Res. Lett., 13 (10), 991-994.

Brandes, E. A., G. Zhang, and J. Vivekanandan, 2002: Experiments in rainfall estimation with a polarimetric radar in a subtropical environment. J. Appl. Meteor., 41, 674-685.

Bringi, V. N., and V. Chandrasekar, 2001: Polarimetric Doppler Weather Radar: Principles and Applications. Cambridge University Press, 636 pp.

— - G. J. Huang, V. Chandrasekar, and R. Gorgucci, 2002: A methodology for estimating the parameters of a gamma raindrop size distribution model from polarimetric radar data: Application to a squall-line event from the TRMM/Brazil campaign. J. Atmos. Oceanic Technol., 19, 633-645.

_ , V. Chandrasekar, J. Hubbert, E. Gorgucci, W. L. Randeu, and M. Schoenhuber, 2003: Raindrop size distribution in different climatic regimes from disdrometer and dual-polarized radar analysis. J. Atmos. Sci., 60, 354-365.

Campos, E., and I. Zawadzki, 2000: Instrument uncertainties in $Z-R$ relations. J. Appl. Meteor., 39, 1088-1102.

Cao, Q., G. Zhang, E. Brandes, T. Schuur, A. Ryzhkov, and K. Ikeda, 2008: Analysis of video disdrometer and polarimetric radar data to characterize rain microphysics in Oklahoma. J. Appl. Meteor. Climatol., 47, 2238-2255.

Cifelli, R., W. A. Petersen, L. D. Carey, S. A. Rutledge, and M. A. F. Silva Dias, 2002: Radar observations of the kinematic, microphysical, and precipitation characteristics of two MCSs in TRMM-LBA. J. Geophys. Res., 107 (10), doi:10.1029/ 2000JD000264.

Donnadieu, G., 1980: Comparison of results obtained with the VIDIAZ spectropluviometer and the Joss-Waldvogel rainfall disdrometer in a "rain of a thundery type." J. Appl. Meteor., 19, 593-597.

Gunn, R., and G. D. Kinzer, 1949: The terminal velocity of fall for water droplets in stagnant air. J. Meteor., 6, 243-248.

Hauser, D., P. Amayenc, B. Nutten, and P. Waldteufel, 1984: A new optical instrument for simultaneous measurement of raindrop diameter and fall speed distributions. J. Atmos. Oceanic Technol., 1, 256-269.

Hou, A., G. S. Jackson, C. Kummerow, and C. M. Shepherd, 2008: Global precipitation measurement. Precipitation: Advances in Measurement, Estimation, and Prediction, S. Michaelides, Ed., Springer, 131-169.

Iguchi, T., T. Kozu, R. Meneghini, J. Awaka, and K. Okamoto, 2000: Rain-profiling algorithm for the TRMM precipitation radar. J. Appl. Meteor., 39, 2038-2052.

Joss, J., and A. Waldvogel, 1967: Ein spectrograph für Niederschlasgstropfen mit automatischer Auswertung (A spectrograph for the automatic analysis of raindrops). Pure Appl. Geophys., 69, 240-246.

Kozu, T., T. Iguchi, T. Kubota, N. Yoshida, S. Seto, J. Kwiatkowski, and Y. N. Takayabu, 2009a: Feasibility of raindrop size distribution parameter estimation with TRMM precipitation radar observations of shallow convection with a rain cell model. J. Meteor. Soc. Japan, 87A, 53-66.

— _ _ - T. Shimomai, and N. Kashiwagi, 2009b: Raindrop size distribution modeling from a statistical rain parameter relation and its application to the TRMM precipitation radar rain retrieval algorithm. J. Appl. Meteor. Climatol., 48, 716724.

Krajewski, W. F., and Coauthors, 2006: DEVEX-disdrometer evaluation experiment: Basic results and implications for hydrologic studies. Adv. Water Resour., 29, 311-325. 
Kruger, A., and W. F. Krajewski, 2002: Two-dimensional video disdrometer: A description. J. Atmos. Oceanic Technol., 19, 602-617.

Lee, C. K., G. W. Lee, I. Zawadzki, and K. E. Kim, 2009: A preliminary analysis of spatial variability of raindrop size distributions during stratiform rain events. J. Appl. Meteor. Climatol., 48, 270-283.

Lee, G. W., and I. Zawadzki, 2005a: Variability of drop size distributions: Timescale dependence of the variability and its effects on rain estimation. J. Appl. Meteor., 44, 241-255.

$\longrightarrow$, and $-2005 \mathrm{~b}$ : Variability of drop size distributions: Noise and noise filtering in disdrometric data. J. Appl. Meteor., 44, $634-652$.

Löffler-Mang, M., and J. Joss, 2000: An optical disdrometer for measuring size and velocity of hydrometeors. J. Atmos. Oceanic Technol., 17, 130-139.

Mardiana, R., T. Iguchi, and N. Takahashi, 2004: A dual-frequency rain profiling method without the use of a surface reference technique. IEEE Trans. Geosci. Remote Sens., 42, 2214-2225.

Meneghini, R., and L. Liao, 2007: On the equivalence of dualwavelength and dual-polarization equations for estimation of raindrop size distribution. J. Atmos. Oceanic Technol., 24, 806-820.

Miriovsky, B. J., and Coauthors, 2004: An experimental study of small-scale variability of radar reflectivity using disdrometer observations. J. Appl. Meteor., 43, 106-118.

Munchak, S. J., and A. Tokay, 2008: Retrieval of raindrop size distribution from simulated dual-frequency radar measurements. J. Appl. Meteor. Climatol., 47, 223-239.

Nakamura, K., and T. Iguchi, 2007: Dual-wavelength radar algorithm. Measuring Precipitation from Space, V. Levizanni, P. Bauer, and F. J. Turk, Eds., Springer, 225-234.

Nespor, V., W. F. Krajewski, and A. Kruger, 2000: Wind-induced error of raindrop size distribution measurement using a twodimensional video disdrometer. J. Atmos. Oceanic Technol., 17, 1483-1492.

Radhakrishna, B., and T. Narayana Rao, 2010: Differences in cyclonic raindrop size distribution from southwest to northeast monsoon season and from that of noncyclonic rain. J. Geophys. Res., 115, D16205, doi:10.1029/2009JD013355.

Ryzhkov, A., S. E. Giangrande, V. M. Melkinov, and T. J. Schuur, 2005: Calibration issues of dual-polarization radar measurements. J. Atmos. Oceanic Technol., 22, 1138-1155.

Salles, C., and J. D. Creutin, 2003: Instrument uncertainties in $Z-R$ relationships and raindrop fall velocities. J. Appl. Meteor., 42, 279-290.

Sauvageot, H., and J. Lacaux, 1995: The shape of averaged drop size distributions. J. Atmos. Sci., 52, 1070-1083.

Scarchilli, G., E. Gorgucci, and V. Chandrasekar, 1996: Consistency of polarization diversity measurement of rainfall. IEEE Trans. Geosci. Remote Sens., 34, 22-26.
Schönhuber, M., G. Lammer, and W. L. Randeu, 2007: One decade of imaging precipitation measurement by $2 \mathrm{D}$-video-disdrometer. $A d v$. Geosci., 10, 85-90.

Sheppard, B. E., 1990: The measurement of raindrop size distributions using a small Doppler radar. J. Atmos. Oceanic Technol., 7, 255-268.

Thurai, M., W. A. Petersen, A. Tokay, C. Schultz, and P. Gatlin, 2011: Drop size distribution comparisons between Parsivel and 2-D video disdrometers. Adv. Geosci., 30, 3-9.

— , V. N. Bringi, L. D. Carey, P. Gatlin, E. Schultz, and W. A. Petersen, 2012: Estimating the accuracy of polarimetric radarbased retrievals of drop size distribution parameters and rain rate: An application of error variance separation using radarderived spatial correlations. J. Hydrometeor., 13, 1066-1079.

Tokay, A., and D. A. Short, 1996: Evidence from tropical raindrop spectra of the origin of rain from stratiform versus convective clouds. J. Appl. Meteor., 35, 355-371.

— variability of raindrop size distribution. J. Appl. Meteor., 49, 2348-2365.

—, A. Kruger, and W. F. Krajewski, 2001: Comparison of drop size distribution measurements by impact and optical disdrometers. J. Appl. Meteor., 40, 2083-2097.

,-- W. Krajewski, P. A. Kucera, and A. J. Pereira Filho, 2002: Measurements of drop size distribution in the southwestern Amazon basin. J. Geophys. Res., 107, 8052, doi:10.1029/2001JD000355.

_ D. B. Wolff, K. R. Wolff, and P. Bashor, 2003: Rain gauge and disdrometer measurements during the Keys Area Microphysics Project (KAMP). J. Atmos. Oceanic Technol., 20, 1460-1477.

_ , P. G. Bashor, and K. R. Wolff, 2005: Error characteristics of rainfall measurements by collocated Joss-Waldvogel disdrometers. J. Atmos. Oceanic Technol., 22, 513-527.

,-- , and V. L. McDowell, 2010: Comparison of rain gauge measurements in mid-Atlantic region. J. Hydrometeor., 11, 553-565.

Ulbrich, C., and D. Atlas, 1998: Rain microphysics and radar properties: Analysis methods for drop size spectra. J. Appl. Meteor., 37, 912-923.

Vivekanandan, J., G. Zhang, and E. Brandes, 2004: Polarimetric radar estimators based on a constrained gamma drop size distribution model. J. Appl. Meteor., 43, 217-230.

Williams, C. R., A. Kruger, K. S. Gage, A. Tokay, R. Cifelli, W. F. Krajewski, and C. Kummerow, 2000: Comparison of simultaneous raindrop size distributions estimated from two surface disdrometers and a UHF profiler. Geophys. Res. Lett., 27, 1763-1766.

Zhang, G., V. Vivekanandan, and E. Brandes, 2001: A method for estimating rain rate and drop size distribution from polarimetric radar measurements. IEEE Trans. Geosci. Remote Sens., 39, 830-841. 